\title{
Bases romanísticas de la responsabilidad objetiva en los supuestos de daños personales en los contratos de transporte
}

\author{
Olga Marlasca Martínez \\ Profesora doctora de Derecho romano \\ Universidad de Deusto
}

Recibido: 15.10 .08

Aceptado: 04.05.09

\begin{abstract}
Resumen: En el Derecho romano se dieron una serie de recursos jurídicos a favor de los particulares que confiaban sus bienes a determinados profesionales. Uno de estos recursos es el receptum nautarum. Más concretamente, la responsabilidad objetiva que deriva del citado receptum, así como de algunas otras medidas legales procedentes de los textos romanos, viene reelaborándose por la tradición jurídica al compás de los cambios que se van produciendo en la realidad social. Ello justifica el estudio de este tipo de responsabilidad, a partir de la época romana, su influencia en los textos legales medievales y, finalmente, la aplicación del criterio objetivo de responsabilidad en algunos ámbitos de la legislación actual.

Palabras clave: responsabilidad objetiva; textos romanos, época medieval; responsabilidad en el transporte de personas en la legislación actual.

Abstract: In the Roman Law there existed a series of legal measures in favour of the members of the public who entrusted their goods to certain professionals. One of these measures is the receptum nautarum. More exactly, the strict liability which derives from the mentioned receptum, as well as other legal measures coming from the roman texts, is reelaborated by the legal tradition in accordance with the social changes. These points justify the study of this kind of liability starting from the Roman times, its influence in the legal mediaeval texts and, finally, the application of the objective criterion of liability in certain fields of the actual legislation.
\end{abstract}

Key words: strict liability; roman texts; Mediaeval times; liability in the transport of persons in the actual legislation.

Sumario: 1. INTRODUCCIÓN.-2. EL TRANSPORTE MARÍTIMO EN EL DERECHO ROMANO. 1. Importancia del comercio marítimo. 2. Algunas modalidades de contrato en el transporte marítimo 3. Transporte de pasajeros.-3. RECURSOS LEGALES CONTRA LOS NAUTAE EN EL TRANSPORTE MARÍTIMO EN LA ÉPOCA ROMANA. 1. Generalidades. 2. Determinadas actiones in factum como consecuencia de actuaciones delictivas de los nautae. 3. Características de la actio que procede del receptum nautarum.-4. LA REGULACIÓN EN LAS SIETE PARTIDAS.-5. RESPONSABILIDAD DEL PORTEADOR POR LOS DAÑOS PRODUCIDOS POR LA MUERTE O LESIONES DEL VIAJERO EN EL DERECHO ACTUAL. 1. Consideraciones generales acerca del contrato de transporte. 2. La imputación del daño: del 
sistema de responsabilidad por culpa a la responsabilidad objetiva. 3. Responsabilidad por los daños ocasionados a las personas en el transporte terrestre. 4. Responsabilidad por los daños personales como consecuencia del transporte marítimo de viajeros. 5. Responsabilidad por los daños debidos a la muerte o lesiones personales en el transporte aéreo de viajeros.

\section{Introducción}

La actual contratación en masa con las empresas de prestación de bienes y servicios ha dado lugar a que los distintos ordenamientos jurídicos hayan adoptado una serie de medidas para la protección de los derechos de los consumidores y usuarios, considerados en general la parte contratante más débil de la relación contractual ${ }^{1}$. Algunas de estas medidas fueron ya observadas en el Derecho romano a partir del momento en que empieza a haber en la sociedad romana un desarrollo comercial y, sobre todo, marítimo. Precisamente va a ser el pretor el que va a conceder una serie de recursos jurídicos ante las nuevas situaciones que se iban presentando en la realidad social caracterizada por una progresiva expansión económica ${ }^{2}$. Además, algunos de los recursos citados constituyen lo que hoy en día se considera responsabilidad objetiva, esto es, la persona que ha sufrido los daños puede reclamarlos, con independencia de que la parte obligada a su indemnización haya actuado o no con culpa o dolo.

Como es sabido, en la época romana la actividad de los nautae, caupones y stabularii está unida a la del transporte marítimo o terrestre que, junto con el comercio, es lo que motiva la movilidad de las gentes que tienen que desplazarse desde el lugar de su residencia para llevarla a cabo. Más concretamente, la existencia y consideración de los nautas parecen inseparables del comercio marítimo; por otro lado, los caupones y stabularii pueden alojar en mesones y establos a gentes que no desempeñan una actividad mercantil o que sí desempeñan la citada actividad si bien esta sería un incentivo importante para el transporte terrestre ${ }^{3}$.

El presente artículo tiene por objeto analizar una serie de recursos jurídicos, que se dieron ya en la época romana, a favor de los particulares que

\footnotetext{
${ }^{1}$ No obstante, la protección de los consumidores ha de entenderse dentro del marco constitucional económico, y no puede ir contra los principios constitucionales configuradores del modelo económico, GARCía Amigo, M., Condiciones generales de los contratos (Civiles y Mercantiles), Madrid, 1969, pp. 205-ss.

${ }^{2}$ Cf. Salazar Revuelta, M., La responsabilidad objetiva en el transporte marítimo y terrestre en Roma. Estudio sobre el receptum nautarum, cauponum et stabulariorum: entre la utilitas contrahentium y el desarrollo comercial, Madrid, 2007, pp. 39-40.

${ }^{3}$ GiméneZ-Candela, T., Los llamados cuasidelitos, Madrid, 1999, p. 129.
} 
confían sus bienes a determinados profesionales para ser trasladados de un lugar a otro o cuando se alojan en establecimientos de hospedaje o dejan sus animales al cuidado de estos. Algunos de estos recursos van a ser objeto de recepción en textos legales posteriores y dejan asimismo su impronta en el Código civil español. En este sentido podría decirse que se aprecia un paralelismo entre el transporte por mar y el hospedaje. Este paralelismo se ha mantenido en nuestra legislación hasta la actualidad, como demuestra el artículo 1601 del Código civil, que atribuye a los conductores de efectos por tierra o por mar las mismas obligaciones establecidas para los posaderos en cuanto a la responsabilidad por pérdida o deterioro de las cosas que se le confían. Además, algunas de estas medidas que constituyen verdadera responsabilidad objetiva han sido desarrolladas en la actualidad por leyes especiales en una serie de ámbitos, entre ellos en el transporte de personas cuando se producen daños físicos que afectan a los viajeros.

Por otro lado, determinados recursos jurídicos, entre ellos, el receptum nautarum, están muy relacionados con el desarrollo del tráfico comercial marítimo; un comercio a gran escala que planteará todo tipo de problemas jurídicos que el pretor vendrá a resolver con el fin de dar protección a quien se considera que es la parte más débil de la relación contractual. Más concretamente, la responsabilidad objetiva que deriva del receptum nautarum, así como de algunas otras medidas legales procedentes de los textos romanos, viene reelaborándose por la tradición jurídica tomando como base los mencionados textos al compás de los cambios socioeconómicos que se van produciendo en la realidad social. Ello justifica el estudio de este tipo de responsabilidad a partir de la época romana, su influencia en los textos legales medievales y, finalmente, la aplicación del criterio objetivo de responsabilidad en algunos ámbitos de la legislación actual.

\section{El transporte marítimo en el Derecho romano}

\section{Importancia del comercio marítimo}

Es cierto que en el Derecho romano no encontramos una noción de consumo con el significado que posee en la actualidad ${ }^{4}$, ni siquiera un campo

\footnotetext{
${ }^{4}$ Según Ledesma, J. de J., «Bases romanísticas de la legislación protectora del consumidor», en Revista de la Facultad de Derecho de la Universidad de México, 32, (1982) n. ${ }^{\circ} 121$ 123 , p. 343, la explicación no es difícil de encontrar y ello es debido a que «la sociedad romana no es una sociedad de economía de empresa ni tampoco una sociedad estructurada en la economía urbana como hoy entendemos esta expresión. Existe empero otro motivo poderoso. El proceso de diferenciación de lo jurídico ha operado en Roma al interior del Derecho Civil, sin que haya ido demasiado más allá. Prueba de ello es cómo en la Edad Media y principios del Renacimiento, se quiere titular a la legislación de Justiniano con el calificativo de "Civilis"». No obstante lo anterior, el citado autor reconoce que «no es del
} 
jurídico autónomo relativo a la materia $\operatorname{comercial}^{5}$, no obstante, nos presentan los textos una serie de medidas que protegen a los particulares en determinadas situaciones respondiendo a fenómenos típicos de una economía de mercado, que van surgiendo desde el s. III a.C. tiene su auge en los siglos sucesivos y su declive en el s. III d. C. ${ }^{6}$

En este sentido se puede decir que los recursos jurídicos que se ponen a disposición de los particulares que han contratado con un nauta, caupo o stabularius, puede considerarse, sin duda, un ejemplo de protección de los derechos de los que hoy conocemos como de los consumidores. Por ello vamos a ver en los siguientes apartados cómo el pretor interviene en el tráfico jurídico para que el particular pueda demandar a los citados profesionales, y en ocasiones, -como es en el caso del receptum nautarum - sin entrar a valorar su comportamiento, de forma que les va a exigir una responsabilidad que en los derechos modernos se califica de responsabilidad objetiva.

Dada la situación geográfica de Roma, los romanos habían practicado el comercio desde tiempos muy remotos. A lo largo de la República se produjo un fuerte incremento cualitativo y cuantitativo de las actividades comerciales. En ello influyeron una serie de importantes factores como fueron la generalización del uso del dinero, el desarrollo del espíritu de empresa, la práctica de la navegación, la introducción y generalización de las actividades bancarias, etc. ${ }^{7}$

Una actividad económica muy importante y nueva para los romanos fue el comercio marítimo, ejercido originariamente en el Mediterráneo por fenicios y griegos. Conviene destacar que las instituciones comerciales de los romanos surgieron de las instituciones marítimas pues el verdadero comercio, esto es, el comercio al por mayor, es también en el mundo romano o romanizado inseparable de la navegación ${ }^{8}$. Por otro lado, este comercio debió de preocupar más a los juristas romanos que el fluvial o de pequeño cabotaje, de ahí las constantes referencias textuales sobre el transporte marí-

todo difícil encontrar en la milenaria experiencia de ese pueblo normas que de un modo $\mathrm{u}$ otro, se hayan ocupado del asunto», ibidem, p. 339.

${ }^{5}$ Cf. SAlazar Revuelta, M., La responsabilidad objetiva en el transporte marítimo y terrestre en Roma, ob. cit., pp. 42-ss. y la bibliografía que cita la autora en la nota 5, ibidem.

${ }^{6}$ Considera SERrao, F., «Impresa, mercato, diritto. Riflessioni minime», en Mercati permanenti e mercati periodici nel mondo romano. Atti degli incontri capresi di storia dell'economia antica (Capri 13-15 ottobre 1997), a cura di Elio Lo Cascio (Bari 2000), pp. 3167, que las causas de este declive son fundamentalmente las siguientes: «arresto dell'espansione imperialistica, maggiores limitazioni della libera concorrenza e inizio di un regime vincolistico,crisi dell'economia mercantile, crisi del sistema schiavistico», cf., p. 31.

${ }^{7}$ De Churruca, J. y MentXaka, R., Introducción histórica al Derecho romano. 9. ${ }^{\text {ed. }}$ revisada, Bilbao, 2007, p. 54.

${ }^{8}$ BISCARDI, A., «Introduction à l'étude des pratiques commerciales dans l'histoire des droits de l'antiquité», RIDA, Tome 29, Bruxelles, 1982, p. 29. 
timo. Por ello, si nos fijamos en la actividad relacionada con los transportes, el terrestre no tuvo en Roma un desarrollo tan importante como el marítimo, debido a su alto coste e inseguridad ${ }^{9}$; sin embargo, gran parte del comercio interior, donde no existían ríos navegables, se llevaba a cabo mediante caravanas de $\operatorname{carros}^{10}$ que cubrían también las rutas del Oriente ${ }^{11}$.

En cuanto al origen social de las personas que formaban parte de la tripulación de las naves que ejercían el comercio marítimo, interesa poner de relieve que la gran mayoría eran de rango inferior: esclavos, libertos e hijos de libertos ${ }^{12}$; por otro lado, las fuentes epigráficas nos muestran que entre ellos eran frecuentes los nombres de origen oriental ${ }^{13}$; en cambio, las fuentes jurídicas nos informan mejor de su actuación, por lo que se puede afirmar que, si bien los romanos tradicionales ${ }^{14}$-y especialmente los senadores $^{15}$-, estuvieron alejados de los negocios marítimos, del comercio y el transporte, su gestión se encomendaba con frecuencia a los propios libertos y esclavos ${ }^{16}$.

Los textos jurídicos se refieren en ocasiones al personal de una nave y los cometidos que en ella desempeñan: a) dominus navis ${ }^{17}$, como el nombre lo indica, es el propietario de la nave y puede ser al mismo tiempo exercitor navis; b) exercitor navis ${ }^{18}$, es el verdadero empresario naval a quien corresponden la iniciativa y planteamiento de las operaciones que se han de llevar a cabo. El exercitor, como ya se ha dicho, puede ser propietario o usufructuario de la nave; puede tener asimismo la condición de arrendatario, como-

${ }^{9}$ Cf., entre otros, Crook, J. A., Law and life of Rome, London, 1967, p. 223.

${ }^{10} \mathrm{Cf}$. el contenido del texto en Dig. 19,2,60,8.

${ }^{11}$ Respecto al alojamiento en los viajes, quienes no disponían de un alojamiento privado se alojaban en una de las cauponae existentes en las ciudades y caminos, cf. CROOK, J. A., Law and life of Rome, ob. cit., p. 227.

${ }^{12}$ Cf. RougÉ, J., Recherches sur l'organisation du commerce maritime en Mediterranée sous l'Empire romain, París, 1966, pp. 302-ss. No obstante, considera el autor citado que no se puede dar una afirmación categórica ya que en el mundo oriental las actividades en las naves eran realizadas en general por hombres libres de nacimiento y de ascendencia. Incluso en Occidente hay también ejemplos indiscutibles de comerciantes marítimos que eran ingenuos, ibidem, p. 310.

${ }^{13}$ Ibidem, pp. 303-ss.

${ }^{14}$ Ibidem, p. 12.

${ }^{15}$ Como es sabido, la Lex Claudia prohibió a los senadores, no solamente el ejercicio del comercio, sino también, ser propietarios de navíos que pudieran ser utilizados en empresas comerciales.

${ }^{16}$ Vid. Giménez-Candela, T., Los llamados cuasidelitos, ob. cit., p. 131. Del mismo modo, Rougé, J., La marine dans l'antiquité, 1975, p. 190, nos dice que la navegación comercial en la época romana es de tal importancia para la vida económica del Imperio que daba ocupación a numerosas personas generalmente de origen humilde.

${ }^{17}$ Cf. Dig. 27,1,17,6.

${ }^{18}$ Según Ulpiano, en Dig. 14,1,1,15: exercitorem autem eum dicimus, ad quem obventiones et reditus omnes perveniunt [...]. 
datario o puede estar vinculado al dominus navis como filiusfamilias o esclavo, cf. Dig. 14,1,1,16; c) magister ${ }^{19}$ es el gestor de la nave. Es un sustituto, mediante praepositio, del exercitor navis, cf. Dig. 32,65,pr.; d) gubernator es la persona a quien corresponde la dirección técnica de la navegación, Dig. $19,2,13,2 ;$ y f) además están los nautae. Es un término genérico que se refiere a los que están en la nave y participan en la navegación, a veces se refiere solo al amo de la nave ${ }^{20}$.

\section{Algunas modalidades de contrato en el transporte marítimo}

En el Derecho romano el contrato de transporte como tal no existía, sino que se incluía dentro del arrendamiento de obra o de servicios, dependiendo de las condiciones del contrato en particular. Las necesidades del tráfico marítimo crearon diferentes modalidades de arrendamiento: locatio navis y locatio conductio ad onus vehendum ${ }^{21}$.

Si el contrato se realiza bajo la forma de locatio navis, la modalidad más antigua de transporte marítimo, el acto jurídico realizado entre el nauta y el cargador dejaba normalmente al primero libre de responsabilidad en relación con las mercancías. Se enmarca por tanto en la modalidad de locatio conductio rei y las obligaciones que pesaban sobre el nauta eran exigibles por la actio derivada del contrato celebrado, cf. Dig. 14,2,10,1.

En el caso citado de la locatio navis, una nave con su equipaje es puesta a disposición de un cargador, ya sea para un tiempo determinado, ya sea con destino determinado. Por lo tanto, el ámbito de la responsabilidad está perfectamente determinado: obligación de poner el barco a disposición del cargador y de llevarlo a buen puerto por el arrendador; por otra parte, el arrendatario tiene la obligación de pagar la merces y de restituir o de liberar el barco cuando se haya establecido ${ }^{22}$. Hay que tener en cuenta además que, si las mercancías no son restituidas o tiene lugar una restitución defectuosa, el cargador puede reclamar con la actio conducti-si tota navis locata sit, qui conduxit ex conducto etiam de rebus quae desunt agere potest $[. . .]^{23}$-. Por otro lado, la locatio navis dejaba a la responsabilidad de los cargadores todo accidente sobrevenido a la mercancía que no fuese imputable a un fallo en la navegación por el porteador. Es evidente que era un sistema arcaico que debía adaptarse a las necesidades del tráfico.

${ }^{19}$ En Dig. 14,1,1,1, se establece lo siguiente: magistrum navis accipere debemus, cui totius navis cura amndata est.

${ }^{20} \mathrm{Cf}$. el texto de Ulpiano en Dig. 4,9,1,2.

${ }^{21}$ Cf. MÉNAGER, L., «Naulum et receptum rem salvam fore. Contribution a l'étude de la responsabilité contractuelle dans les transports maritimes, en droit romain», en Revue historique de Droit français et étranger, 1960, pp. 386-ss.

${ }^{22}$ Sobre el particular, cf. el texto recogido en Dig. 19,2,61,1.

${ }^{23}$ Dig. 4,9,3,1. 
Otra modalidad del contrato marítimo es la locatio conductio ad onus vehendum: los medios materiales para llevar a cabo el transporte por mar son idénticos a los de la locatio conductio navis, pero sus consecuencias jurídicas son mucho más precisas y, sin duda, muy diferentes. Se trata de un contrato de transporte, pero la responsabilidad que le incumbe al nauta implica a la vez la buena marcha del navío, su conducción al destino marcado (su llegada al destino), Dig. 19,2,13,1, y la entrega de la mercancía en buen estado.

La existencia de un contrato de locatio ad onus vehendum marca un progreso grande con relación a la técnica primitiva del arrendamiento del barco, ya que permitirá accionar en los casos de accidentes sobrevenidos tanto por el estado del barco, como por un defecto de navegación y, sobre todo, como consecuencia de los actos del armador que hayan producido daños o pérdidas en las mercancías transportadas. La acción que tiene a su favor el cargador es la actio ex locato -si vero res perferendas nauta conduxit ex locato convenietur-. La elaboración de la teoría de la custodia y de la noción de responsabilidad precisaron poco a poco los grados de evolución de la responsabilidad del armador, en los términos a los que nos vamos a referir más adelante.

Esta nueva modalidad de transporte en el ámbito romano se enmarca en la locatio conductio operis, que es la locación de obra ${ }^{24}$. En esta modalidad de locatio conductio es el locator quien paga la merced por la obra cuya ejecución encarga. La operación del conductor puede ser muy variada, ya que además de transportar puede fabricar, curar, reparar, instruir, hospedar, medir, etc.

Cuando el transporte era gratuito, los romanos lo encuadraban en el contrato real de depósito; en estos casos dice Pomponio que se pudo ejercitar la acción del depósito ${ }^{25}$. Se trata de un depósito en el que las cosas depositadas se devolvían en lugar distinto y con frecuencia a otra persona que no era el depositante.

\section{Transporte de pasajeros}

A partir del momento en que se ha comenzado a concebir un acto de alquiler marítimo más perfeccionado, se va operando una asimilación entre el contrato de transporte de mercancía locatio ad onus vehendum y el contrato de transporte de pasajeros, locatio ad vectorem vehendum.

Son frecuentes los textos del Digesto que se refieren al transporte de pasajeros y la responsabilidad correspondiente. Así, un texto de Ulpiano en Dig. 19,2,13,2, en caso de pérdida de la nave por culpa del patrón, los transportados tendrán contra él la acción de locación. Del mismo modo, Paulo en

${ }^{24}$ Entre otros, véase, D’ORs, A., Derecho privado romano, Pamplona, 1986, p. 560.

${ }^{25}$ Cf. Dig. 4,9,3,1. 
los Comentarios al Edicto en Dig. 14,2,2, pr. -citado anteriormente- se refiere de forma expresa a los pasajeros que toman una nave en arriendo; en los casos en que haya que recurrir a la echazón para aligerar la nave, el patrón ha de tener contra los pasajeros la acción de locación. De nuevo, en el parágrafo 2 del citado texto se refiere a la echazón de las mercancías en una nave en la que han embarcado diversos géneros de mercancías, así como también pasajeros libres y esclavos.

El importe de la echazón debe distribuirse conforme al precio de las cosas transportadas. De las personas libres no puede hacerse estimación alguna. Por otro lado, en Dig. 14,2,2,1, el texto de Paulo presenta el caso de un navío que ha sufrido algún daño y este daño no se considera avería común. Ahora bien, continúa el texto del citado jurista diciendo que si el daño se ha producido como consecuencia de una decisión tomada por los pasajeros o impuesta por una situación peligrosa debe ser resarcido.

A los pasajeros de una nave se alude asimismo en Dig. 4,9,1, 8, al referirse el texto a la responsabilidad del naviero por custodia en cuanto a los bienes que se han introducido en la nave y debe responder no solo de la conducta de los marineros, sino también de los pasajeros. En otro orden de cosas, en el texto de Ulpiano de los Comentarios al Edicto, libro 28 y contenido en Dig. 14,1,1,12, se está refiriendo a naves que son propias para transportar mercancías (pueden no admitir pasajeros) y otras admiten pasajeros.

Al transporte de viajeros se alude también en otro texto, perteneciente asimismo a Ulpiano, contenido en Dig. 19,2,19,7, donde se presenta el supuesto del nacimiento de un niño -si quis mulierem vehendam navi conduxisset...-, y se considera que nada se debe pagar por el nuevo pasajero.

Finalmente, en el supuesto de haber viajado de forma gratuita ${ }^{26} \mathrm{y}$ haber sufrido daños se le conceden al viajero las mismas acciones que si hubiese contratado el transporte con el patrón del barco.

\section{Recursos legales contra los 'nautae' en el transporte marítimo en la época romana ${ }^{27}$}

\section{Generalidades}

Centrándonos concretamente en la responsabilidad de los nautae, conviene destacar que el Derecho romano no crea al principio un régimen espe-

\footnotetext{
${ }^{26}$ Dig. 4,9,6,pr.

${ }^{27}$ Un estudio riguroso y seriamente meditado acerca de la responsabilidad de los nautae, caupones y stabularii en la época romana ha realizado recientemente SALAZAR REVUELTA, M., La responsabilidad objetiva en el transporte marítimo y terrestre en Roma. Estudio sobre el receptum nautarum, cauponum et stabulariorum: entre la utilitas contrahentium y el desarrollo comercial, Madrid, 2007.
} 
cial para exigir responsabilidad a los nautae, sino que somete a las normas comunes la responsabilidad que por razón de sus actividades pueda surgir. De esta manera, el cargador de las mercancías disponía de una serie de medidas contra el nauta: concretamente, tiene la posibilidad de ejercitar la actio depositi directa, si se han observado las formalidades establecidas para el depósito; puede ejercitar asimismo la actio locati directa, si se ha pactado un contrato de arrendamiento; también procedería interponer la actio furti si las mercancías le hubieran sido sustraídas o la actio damni si hubieran sufrido daños.

Ahora bien, todos estos medios adolecían de un grave inconveniente, ya que el dueño de las mercancías no podía dirigirse contra el nauta fundándose solo en el oficio o industria de este, sino que tenía que demostrar la existencia de un contrato y su incumplimiento por parte de aquel. Por lo que se acaba de decir, se comprende que no resultaba demasiado favorable la posición de quien contrataba con un nauta el traslado de mercancías de un puerto a otro en las etapas más antiguas de la actividad marítima.

Con el paso del tiempo no podía perdurar tal estado de cosas, de tal forma que una serie de razones contribuyeron a que se hiciera más severa y rígida la responsabilidad de los nautae ${ }^{28}$. El derecho honorario estableció una responsabilidad especial con respecto a los objetos que se entregaban para su traslado. El origen de este sistema de responsabilidad parece que fue la costumbre de comprometerse los responsables de la nave a cuidar de tales cosas, de palabra o en anuncios al celebrar el contrato (salva fore recipere). De esta forma, se comprometían los navieros (también los posaderos) a devolver sanas y salvas las mercancías y demás cosas del pasajero, y contraían como consecuencia de este compromiso una responsabilidad especial.

La citada costumbre establecida en las naves y mesones, y convertida en práctica habitual tácita, llega un momento en que es recogida en el Edicto

${ }^{28}$ GoldSCHMIDT, L., «Das receptum, nautarum, cauponum, stabulariorum. Eine Geschichlitch-Dogmatische Abhandlung», en Zeitschrift für das Gesammte Handelsrecht. T. III, Stuttgart,1860, p. 61.

${ }^{29} \mathrm{Se}$ suele situar el edicto que introdujo el receptum nautarum en una época anterior al siglo I. a. C., precisamente en un momento en que la navegación marítima está en continuo desarrollo (después de la finalización de las guerras Púnicas), con la finalidad de estimular el comercio a gran escala. No obstante, no es posible establecer una fecha exacta debido a la falta de datos concretos., vid. SAlazAr Revuelta, M., «La responsabilidad objetiva ex recepto como fundamento jurídico de la protección a terceros en el Derecho comercial romano y su recepción en el Código civil español», en las Actas del IX Congreso Internacional y XII Iberoamericano de Derecho romano: «El Derecho comercial, de Roma al Derecho moderno», celebrado los días 1, 2 y 3 de febrero de 2006. Vol. II, Las Palmas de Gran Canaria, 2007, p. 900 y la bibliografía que allí cita la autora. En el Derecho clásico el principio se amplió, interpretándose en el sentido de que la simple entrega de las cosas del huésped eran causa suficiente para la responsabilidad, y de aquí que se considerara no ser necesaria una declaración expresa del naviero u hostelero asumiendo la responsabilidad de la guarda de aquellas, cf. Dig. 4,9,1,1; eod., 6 y 8. 
pretorio $^{29}$. De esta manera vemos que en el texto recogido en el Digesto de Justiniano, bajo la rúbrica Nautae, caupones, stabularii ut recepta restituant, concretamente en Dig. 4,9,1, pr., procedente del texto de Ulpiano de los Comentarios al Edicto, libro 14, se establece lo siguiente: Ait praetor: Nautae, caupones, stabularii quod cuiusque salvum fore receperint nisi restituent, in eos iudicium dabo.

Se desprende de lo anterior algunas consecuencias ${ }^{30}$ : que el receptum no podía considerarse como una especie de contrato peculiar e independiente; y que sus principios no eran suficientes para regular jurídicamente las relaciones de tráfico por él abarcadas, sino que estas habían de quedar sometidas a las normas civiles que gobernaran la institución respectiva, toda vez que el receptum se limitaba a modificar sus preceptos en lo que respecta a la responsabilidad.

La actio in factum que el pretor concedía en virtud del receptum era más severa que las procedentes del depósito o del arrendamiento y obligaba a la restitución de las cosas o de su valor in simplum, así como al resarcimiento, en su caso, de los daños que hubieren sufrido los efectos del cargador. Además de esta medida descrita, reconoció el pretor al dueño de las mercancías transportadas, como vamos a ver más adelante, una acción penal adversus nautas, encaminada a que aquel fuera indemnizado in duplum con relación al daño que hubieren causado las personas por quienes debía responder el nauta.

Veamos a continuación de forma más detallada la responsabilidad delictiva de los nautae (en los casos de hurto y daños ocasionados en las cosas transportadas) en el ejercicio de su actividad, así como aquella que deriva como consecuencia del llamado receptum nautarum (similar al receptum cauponum et stabulariorum).

2. Determinadas 'actiones in factum' como consecuencia de actuaciones delictivas de los 'nautae'

Por lo que respecta a la responsabilidad de los nautae, su conducta en relación con las mercancías que eran propiedad de los cargadores podía pasar a la zona delictiva. El responsable de la nave o el personal al servicio de esta podía robar las cosas o destrozarlas o dañarlas dolosamente. En tales hipótesis, como vamos a ver en las siguientes líneas, el pretor no se conformó con aplicar las antiguas acciones conocidas por el ius civile.

En primer lugar, conviene cuestionarse por qué se multiplicaron en el Derecho romano los recursos jurídicos contra los nautae, caupones y stabu-

${ }^{30}$ Vid. GoldSCHMIDT, L., «Das receptum, nautarum, cauponum, stabulariorum. Eine Geschichlitch-Dogmatische Abhandlung», ob. cit., pp. 63-64. 
larii, es decir, la razón de que junto a una acción civil de hurto y damnum y una responsabilidad especial nacida del receptum nautarum, cauponum et stabulariorum, se diese además una actio in factum especial dirigida a reprimir los hurtos o daños que se producían en la nave (también en un albergue y en un establo). La respuesta podría ser la siguiente: es razonable pensar que se pretendió dotar con ella de mayor seguridad a los propietarios de las mercancías cargadas en una nave; por ello el pretor quiso crear un recurso que, a semejanza del receptum, del que procede una responsabilidad objetiva por custodia, permitiera reprimir los actos delictivos incluso cometidos por terceros, lo que suponía ya una cierta madurez del pensamiento jurídico ${ }^{31}$.

Como se acaba de decir, es cierto que los nautae que no restituían las mercancías que se les habían entregado para su transporte podían ser perseguidos por la actio furti de derecho civil. Ahora bien, hay que tener en cuenta que la actio furti es una acción de carácter penal, rigurosamente personal que no puede ser intentada más que contra el autor del robo o de la sustracción. Tal vez en raras ocasiones el patrón de la nave (también el posadero o el dueño del establo) era perseguido como autor. En la mayor parte de los casos el robo era cometido por un esclavo o por un empleado libre contratado por el naviero. Más concretamente, si el robo era cometido por un esclavo al servicio del patrón, la actio furti puede ser intentada contra él; pero si el robo ha sido cometido por otra persona, no hay actio furti contra el responsable de la nave.

Por otra parte, en todos los casos, hay que contar con las dificultades de la prueba. La totalidad o parte de las mercancías han sido sustraídas y no pueden ser entregadas a su dueño: con frecuencia será muy difícil saber cómo han desaparecido y probarlo. Parece justo hacer al naviero responsable de esta desaparición y de intentar contra él la actio del hurto, incluso si él no había cometido el citado acto ilícito, e incluso si el autor del hurto no estaba en su poder, o si el autor del delito mencionado era desconocido. Es el pretor quien en su edicto realizó esta extensión de la actio furti. Probablemente la realizó en primer lugar contra los nautae. Más tarde se asimilaron a los transportistas por mar los posaderos y los dueños de establos; de esta manera, las reglas del transporte marítimo han sido extendidas a las necesidades de los transportes terrestres.

\section{1) 'ACtio FURTI ADVERSUS NAUTAS, CAUPONES ET STABUlarios'}

Hay que destacar, en primer lugar, que la mencionada actio in factum furti adversus nautas, caupones et stabularios nos ha sido transmitida por Ulpiano (38 ad edictum) en Dig. 47,5,1, pr. donde se recoge el texto edictal;

${ }^{31}$ Cf. Giménez-Candela, T., Los llamados cuasidelitos, ob. cit., p. 133. 
los compiladores dedicaron el título 47,5 del Digesto al Edicto, y a su comentario por Ulpiano los parágrafos 1-6. Establece el texto en Dig. 47,5,1 pr. $^{32}$, que se dará acción contra los que estén al frente de una nave, posada o establo si cualquiera de las personas de su dependencia ha cometido un hurto, tanto si se ha llevado a cabo con la complicidad del exercitor o de alguno de la tripulación. En las siguientes líneas, vamos a centrar la atención fundamentalmente en los nautae.

Comenzamos precisamente teniendo en cuenta una serie de cuestiones: hay que destacar que el citado texto, en esta forma de redacción contiene algunas deficiencias; concretamente, la primera parte tiene diferente construcción que la segunda. 1) En primer lugar, leemos la frase: factum esse dicetur, en la segunda, factum sit. 2) Además, los supuestos de categorías de profesiones, tampoco es igual: alude a tres categorías de profesiones en la primera parte, en cambio, una sola, la de armadores, en la segunda. 3) Por otro lado, hay que destacar además que el edicto es incompleto, hay que ver en Dig. 47,5,1,2, ${ }^{33}$ donde establece que la acción es al doble.

Es evidente que el texto está retocado, pero ¿en qué sentido? Independientemente de algunas hipótesis, considera Huvelin ${ }^{34}$ que había en el propio edicto ciertas deficiencias de redacción como consecuencia de que los caupones y los stabularii habían sido añadidos a los nautae y se habían añadido por esto en proposiciones separadas las condiciones propias de las acciones que les correspondían.

De esta forma, Ulpiano, que en el libro 38 ad edictum comenta este edicto en su conjunto, se ha referido en primer lugar a la parte del edicto relativa a los nautae. Es el objeto de los párrafos 1-5 del texto. Después de terminar con los nautae, continúa en el parágrafo 6 su comentario respecto a los caupones, reproduciendo probablemente los términos del edicto: el mesonero responde del acto de aquellos que tiene en su mesón para su servicio, y también de los que están allí hospedados; pero no del acto de los viajeros [...]. Es probable que en una tercera parte de su comentario Ulpiano reprodujese los términos del edicto relativos a los stabularii. Ahora bien, según vemos en el Digesto, los compiladores de Justiniano han cortado esta parte del texto, sin duda porque la consideraban inútil ${ }^{35}$. Por otra parte, en el párrafo $3^{36}$, los compiladores han añadido las palabras vel caupo, ya que al final del párrafo se habla solamente del exercitor.

${ }^{32}$ El texto contenido en Dig. 47,5,1, pr. establece lo siguiente: In eos qui naves, cauponas, stabula exercebunt, si quid a quoque eorum, quosve ibi habebunt, furtum factum esse dicetur, iudicium datur, sive furtum ope, consilio exercitoris factum sit, sive eorum cuius, qui in ea navi navigandi causa esset.

${ }^{33}$ El texto contenido en Dig. 47,5,1,2, establece lo siguiente: Et est in duplum actio.

${ }^{34}$ Cf. Huvelin, Paul, Études d'histoire du droit commercial romain, París, 1929, p. 121.

${ }^{35}$ Ibidem, 122. 
Otro aspecto que conviene tener en cuenta tiene relación con el tipo de responsabilidad del patrono. Si tomamos como base los textos podría pensarse que se trata de una responsabilidad por culpa. Pero vamos a ver que, sobre este punto, los textos están interpolados y Justiniano ha querido introducir la idea de la culpa del responsable. Veamos algunos parágrafos. En primer lugar, en el texto de Ulpiano (38 ad edictum) contenido en Dig. 47,5,1,4, se establece lo siguiente: Quod si receperit salvum fore caupo vel nauta, furti actionem non dominus rei surreptae, sed ipse habet, qui recipiendo periculum custodiae subit. El pasaje citado está interpolado. Ulpiano compara la acción de la que va a hablar (actio furti adversus nautas) con la acción nacida del receptum. En el receptum, como vamos a ver en el siguiente apartado con más detenimiento, el dueño responde de su empleado en razón de la custodia, a la que está obligado, responde en su nombre y no puede liberarse con el abandono del esclavo. En cambio, con la acción penal, responde alieno nomine, por tanto, se puede liberar de responsabilidad con el abandono del esclavo, según se establece en Dig. 47,5, 1, $5^{37}$.

Se plantea también la cuestión de saber por qué el dueño responde con tanto rigor tratándose de esclavos ajenos y empleados libres, y con poco cuando se trata de esclavo propio. La respuesta que se da en el propio texto se basa sobre la idea de la culpa in eligendo, ya que al haberse empleado a un hombre libre, el responsable ha debido informarse de sus cualidades; asimismo si ha empleado a un esclavo ajeno, responderá como de un hombre libre. No obstante, tratándose de un esclavo de su propiedad se le debe disculpar.

Hay que destacar asimismo del contenido de los textos, lo que se establece concretamente en el párrafo $6^{38}$ : después de referirse al mesonero que no responde por el robo cometido por el viator, es decir por el viajero de paso y ello resulta sin duda de los términos del edicto y de la fórmula, sin que tuvieran la necesidad de justificarlo ${ }^{39}$, seguidamente nos dice que en la nave tampoco se responde del acto de los pasajeros. Justiniano ha encontrado una justificación, en la línea de lo que veíamos anteriormente. Los profesionales a los que nos hemos referido no tienen la facultad de elegir o rechazar al viajero y, por consecuencia, no responde. Pero, en cambio, puede elegir a las

\footnotetext{
${ }^{36} \mathrm{Cf}$. Dig. 47,5,1, 3, donde se establece lo que sigue: Cuum enim in caupona vel in navi res perit, ex edicto praetoris obligatur exercitor navis vel caupo, ita ut in potestate sit eius, cui res surrepta sit, utrum mallet cum exercitore honorario iure an cum fure iure civili experiri.

${ }^{37}$ Dig. 47,5,1, 5: Servi vero sui nomine exercitor noxae dedendo se liberat [...].

${ }^{38}$ En Dig. 47,5,1, 6, se establece lo siguiente: Caupo praestat factum eorum, qui in ea caupona eius cauponae exercendae causa ibi sunt, item eorum, qui habitandi causa ibi sunt; viatorum autem factum non praestat; namque viatorem sibi eligere caupo vel stabularius non videtur, nec repellere potest iter agentes, inhabitatores vero perpetuos ipse quodammodo elegit, qui non reiecit, quorum factum oportet eum praestare [...].

${ }^{39}$ Cf. Huvelin, P., Études d histoire du droit commercial romain, ob. cit., p. 124.
} 
otras personas (huéspedes, empleados) y responde por tanto por culpa in eligendo.

Nos referimos a continuación a otros dos textos contenidos en el Digesto, asimismo interpolados, y que se refieren a las actiones furti et damni adversus nautas, caupones et stabularios. Uno de ellos está recogido concretamente en Dig. 44,7,5,6, perteneciente a Gayo, libro 3 aureorum, que tiene relación precisamente con el daño o el robo cometido en una nave, mesón o establo por alguno de sus empleados, haciendo responsable al exercitor navis, al mesonero o al dueño del establo respectivamente. Tanto en el texto citado como en las Instituciones de Justiniano, se da como justificación de esa responsabilidad que existe una cierta culpa en el naviero, al servirse de hombres deshonestos (malorum hominum, dice el texto) como empleados.

Por otra parte, en Dig. $14,1,1,2^{40}$, se recoge el texto de Ulpiano, correspondiente al libro 28 ad edictum, donde se establece asimismo que el patrón debe tener cuidado de no emplear gente deshonesta. Si los emplea sale por ello responsable; por tanto, procede el ejercicio de la actio in factum contra el citado empleador. Según lo que se ha dicho en las anteriores líneas, se considera como establecido que los textos que hacen descansar la actio furti adversus nautae (del mismo modo es ampliable a los caupones et stabularii) sobre una idea de culpa son interpolados ${ }^{41}$. Esta acción establece un caso de responsabilidad objetiva, no subjetiva. En definitiva, se puede decir en este caso de la citada actio que se trata de una acción penal por sus orígenes ${ }^{42}$. Pero cuando se ha comenzado a exigir la mala intención como elemento subjetivo de todo delito, no siempre se ha encontrado este elemento en la responsabilidad de los profesionales a los que nos estamos refiriendo (del nauta, del caupo y del stabularius). Entonces se ha admitido que la acción nacía quasi ex maleficio ${ }^{43}$. Además, como ya se ha venido diciendo, la actio furti adversus nautas es redactada como actio in factum y por el doble del valor de las cosas hurtadas.

Así pues, «el ámbito inicial del edicto consistía en fijar una responsabilidad del dueño por el hurto cometido en la nave, albergue o establo de modo objetivo, es decir, sin intervención de ningún elemento subjetivo de responsabilidad, dolo o culpa; la mención de la complicidad del dueño pudo reali-

${ }^{40}$ Dig. 14,1,1,2: Sed si cum quolibet nautarum sit contractum, non datur actio in exercitorem, quamquam ex delicto cuiusvis eorum qui navis navigandae causa in nave sint, detur actio in exercitorem; alia enim est contrahendi causa, alia deliquendi, si quidem qui magistrum praeponit, contrahi cum eo permittit, qui nautas adhibet, non contrahi cum eis permittit sed culpa et dolo carere eos curare debet.

${ }^{41}$ Cf. Huvelin, P., Études d'histoire du droit commercial romain, ob. cit., p. 126.

${ }^{42}$ Cf. Ibidem.

${ }^{43}$ En Dig. 44,7,5,6, se establece Item exercitor navis aut caupones aut stabuli de damno aut furto, quod in nave aut caupona aut stabulo factum sit, quasi ex maleficio teneri videtur $[\ldots]$. 
zarse en un estadio posterior a la promulgación del edicto, pero estaba ya implícita en el propio texto edictal» ${ }^{44}$. Esto puede explicar en parte la razón de ser de la citada acción en el edicto, junto a la acción civil de hurto, pues «tendría la ventaja sobre esta de poder darse directamente contra el nauta (también contra el caupo y el stabularius) sin necesidad de probar el dolo o la culpa del mismo, ni la identidad personal del autor del hecho delictivo, tantas veces difícil en la práctica en un ámbito como una nave, posada o un establo» ${ }^{45}$.

Más concretamente podría plantearse la siguiente situación ${ }^{46}$ : si es el armador mismo el que cometía el hurto, el cargador podría perfectamente entablar contra él la actio furti corriente. Si el delito era obra de un esclavo de dicho armador, también podría este ser demandado por ella, aunque ya en esta hipótesis, la entrega en noxa del esclavo -cuyo valor podría compensar de la pérdida sufrida a la víctima del hurto- proporcionaba al exercitor el medio de liberarse de responsabilidad o, si se quiere, de limitar esta a la pérdida del esclavo. Pero muchas veces el hurto sería cometido por personal no esclavo, y entonces solo el autor material del hecho -frecuentemente de dudosa o nula solvencia- podría ser demandado por la actio furti ordinaria. Y en todo caso siempre resultaría difícil la prueba necesaria para la imputación del hecho. De esta forma, la modalidad de la actio furti especial, prometida por el pretor para los casos en los que intervenían los citados empresarios (nautae, caupones et stabularii), es decir, la actio furti adversus nautas, caupones et stabularios por la cual se obtenía el doble del valor de las cosas hurtadas, remediaba tales inconvenientes ${ }^{47}$.

El pretor estableció así una responsabilidad penal objetiva, con una gran facilidad de obtención para el cargador que la exigía; responsabilidad a la que los compiladores bizantinos, modificando los textos clásicos, procuraron dotar de una cierta base subjetiva como figura de culpa in eligendo de los citados profesionales ${ }^{48}$.

Finalmente, por lo que respecta a la posible concurrencia de la acción civil de hurto y la acción pretoria adversus nautas, caupones et stabularios,

${ }^{44}$ GiméneZ-Candela, T., Los llamados cuasidelitos, ob. cit., p. 135.

${ }^{45}$ Ibidem.

${ }^{46}$ ArIas Ramos, José, El transporte marítimo en el mundo romano. Discurso de apertura del Curso 1948-1949. Universidad de Valladolid, p. 51.

${ }^{47}$ En Dig. 47,5,1, pr., el texto de Ulpiano correspondiente al libro 38 ad edictum establece que in eos, qui naves, caupona, stabula exercebunt, si quid a quoque eorum, quove ibi habebunt, furtum factum esse dicetur [...].

${ }^{48}$ Cf. ARIas Ramos, José, El transporte marítimo en el mundo romano, ob. cit., p. 52.

${ }^{49}$ Es precisamente en Dig. 47,5,1, 3, donde Ulpiano prosigue su comentario al edicto y establece lo siguiente: Cum enim in caupona vel navi res perit, ex edicto praetoris obligatur exeritor navis vel caupo ita [...]. 
no hay tal, ya que se indica en el párr. $3^{49}$ que el demandante tiene derecho a elegir entre entablar una u otra acción, lo cual quiere decir que no se produce aquí una verdadera concurrencia de las acciones civil y pretoria, sino que se trata simplemente de un derecho del demandante ${ }^{50}$. Se podría decir que la mencionada acción pretoria contra los navieros, posaderos y dueños de establos es subsidiaria de la actio furti, y se ejercita cuando esta resulta difícil poder entablarla, por ejemplo, por no conocerse la identidad del ladrón ${ }^{51}$.

\section{2) ACTIO DAMNI ADVERSUS NAUTAS, CAUPONES ET STABULARIOS}

Se utiliza esta expresión para designar brevemente la acción en cuestión; no obstante, consideran algunos autores ${ }^{52}$ que tal vez no aparecía en los textos. Las mercancías transportadas en una nave podían ser objeto no solamente de un robo, sino igualmente sufrir un damnum iniuria datum y, también en este caso, al igual que en el del furtum, interesaba hacer al empresario responsable no solamente de las actuaciones de sus esclavos, sino de los hechos de las personas libres que podía emplear. El pretor había creado una acción que se podía ejercitar contra los citados profesionales por los daños causados, análoga a la acción de robo que se ha visto en el epígrafe anterior. Pero esta acción no llevaba nombre especial. Hay sobre este punto una diferencia notable con la acción de hurto.

Según se dijo anteriormente, el edicto furti adversus nautas, caupones et estabularios forma el objeto de un título especial del Digesto $(47,5)$; está situado en el Edicto Perpetuo después de los edictos generales sobre el furtum. Ulpiano lo estudiaba en su libro 38 ad edictum, donde él continuaba el comentario de estos edictos generales comenzado en su libro 37. Al contrario, las disposiciones relativas a la acción penal dirigida a los nautae, caupones et stabularii, por daños causados a sus clientes, no figuran en un título especial del Digesto, sino que están comprendidas en su libro 4,9, consagrado al receptum de los citados empleadores. En el Edicto Perpetuo ellas figuran en el anexo al edicto sobre el delito de daños ${ }^{53}$. Todo lleva a creer que no había edicto especial sobre la materia, ya que, si no, la ausencia de un título especial en el Digesto se justificaría mal.

${ }^{50}$ Cf. De Robertis, F. M., «Receptum nautarum». Studio sulla responsabilità dell'armatore in diritto romano, con riferimento alla disciplina concernente il «caupo»e lo «stabularius», Bari, 1952, p. 121; GIMÉNEZ-CANDELA. T., Los llamados cuasidelitos, ob. cit., p. 136.

${ }^{51}$ Giménez-Candela. T., Los llamados cuasidelitos, ob., cit., p. 136.

${ }^{52}$ Cf. Huvelin, P., Études d'histoire du droit commercial romain, ob. cit., p. 127.

${ }^{53}$ Cf. Lenel, O., Das Edictum Perpetuum, Leipzig, 1927 = Aalen, 1956, pp. 205-ss. 
Los textos sobre la actio damni adversus nautae han sido retocados al igual que los de la actio furti adversus nautae y en el mismo sentido; también aquí, Justiniano ha querido fundar la responsabilidad sobre una idea de culpa. Veamos en primer lugar un texto de Ulpiano en el libro 18 ad edictum, contenido en Dig. 4,9,7, que tiene relación con los daños causados y la acción correspondiente. La actio damni citada comenzó siendo una actio adversus nautas, se da en los mismos casos que la actio furti adversus nautas, en razón del hecho de las mismas personas (del mismo exercitor y de todas las gentes del mar, hombres libres y esclavos, pero no de los viajeros, cf. Dig. 4,9,7, pr.). Más adelante, la acción se extendió contra los caupones y stabularii ${ }^{54}$ y se trata también aquí de una actio al doble ${ }^{55}$.

Coinciden los estudiosos del texto acerca de su interpolación. Justiniano ha querido alegar la culpa in eligendo para justificar la actio damni adversus nautas, de esta manera en Dig. 4,9,7,4 se establece que por esta acción se obliga el capitán de la nave en nombre propio, a saber, porque lo ha de imputar a su culpa el que empleó tales hombres. La misma idea subyace en un texto de Paulo, contenido en Dig. 4,9,6,3. El texto se inserta dentro del comentario de Paulo a la actio in factum de damno adversus caupones, en el que se reitera que el posadero se responsabiliza de los actos de los que se encuentran en la posada habitandi causa, a su servicio, por ello se excluyen de tal responsabilidad a los que se alojan allí incidentalmente, como, por ejemplo, los viajeros. Por otra parte, en otro texto asimismo de Paulo y recogido en Dig. 4,9,6,pr., se establece que, aun en el supuesto de transporte gratuito, procede la acción penal si se ha causado algún daño: Licet gratis navigaveris, vel in caupona gratis deverteris, non tamen in factum actiones tibi denegabuntur, si damnum iniuria passus es, según el texto.

Las dos acciones citadas, esto es, la actio furti y la actio damni adversus nautae, no han sido introducidas al mismo tiempo en el edicto; es poco probable que se las haya separado, puestas en dos sitios diferentes. Se puede considerar sobre el particular ${ }^{56}$ que la actio damni adversus nautae debe de ser más reciente que la actio furti adversus nautae. Las mismas reglas rigen en las dos acciones, de manera que una las ha tomado de la otra. Además, como estas reglas tienen su fuente en un edicto, podría pensarse que la acción que comporta un edicto es anterior a la otra, aunque las dos acciones deben de tender a aproximarse.

${ }^{54}$ Cf. Dig. 4,9,7,6, en cuyo texto se dice, entre otras cosas lo siguiente: [...] Sed cuum voluntate patris vel domini servus vel filius exercent navem, vel cauponam, vel stabulum, puto etiam hanc actionem in solidum eos pati debere, quasi omnia, quae ibi contingunt, in solidum receperint.

${ }^{55}$ En Dig. 4,9,7,1: Haec actio in factum in duplum est.

${ }^{56}$ Huvelin, P., Études d'histoire du droit commercial romain, ob. cit., p. 130.

${ }^{57}$ Dig. 4,9,6,4: Possumus autem furti, vel damni iniuriae actione uti cum nautis, ut certi hominis factum arguamus [...]. 
Finalmente, se plantean en algunos pasajes del Digesto algunos otros aspectos relativos a las acciones a las que nos estamos refiriendo. En uno de los textos, concretamente en Dig. 4,9,6,457 se trata una cuestión importante, la cuestión del cúmulo de las actiones in factum con las acciones civiles de furtum y de damnum. El citado texto está en gran parte interpolado. Ahora bien, hay que destacar que, concretamente, para intentar la actio furti de carácter civil, es necesario poder designar al culpable contra quien se dirige, cosa con frecuencia imposible. Por el contrario, las actiones in factum, como ya se ha venido diciendo, se dirigen contra el responsable de la nave, albergue o establo, sin designar por su nombre al culpable, incluso sin conocerlo.

A modo de resumen, podemos destacar lo siguiente. Similar a lo indicado para el furtum, fue también la ampliación llevada a cabo por el pretor respecto de la vieja acción creada por la lex Aquilia, en el caso del damnum iniuria datum ocasionado en los bienes y cosas dejadas en los establecimientos de los que son responsables los nautae. El nauta podía ser demandado prescindiendo de su culpa en la producción del daño. Y análoga es también la tendencia bizantina a la culpa in eligendo, tendencia que en este caso es del mismo modo acusada por el retoque de los textos ${ }^{58}$.

La única diferencia es que, así como la actio furti adversus nautae se reguló en el Edicto con independencia y tiene en el Digesto un título a ella dedicado, la actio damni en la hipótesis de los empleadores citados anteriormente debió de figurar en el Edicto como un apéndice de la parte destinada al damnum iniuria datum y no hay en el Digesto un título dedicado a la citada acción.

\section{Características de la actio que procede del 'receptum nautarum'}

Si la etapa comercial romana, como se ha dicho anteriormente, comprende aproximadamente desde la mitad del s. III a. C. hasta la mitad del s. III d. C., la actividad del pretor es realmente amplia e importante en el desenvolvimiento de la actividad comercial. El edicto pretorio que introduce el receptum nautarum, cauponum et stabulariorum concede una actio in factum contra los nautae, caupones y stabularii que hayan asumido por medio del receptum la obligación de devolver intactas las cosas que les han sido confiadas.

Un primer aspecto destacable es que el nacimiento del receptum aparece íntimamente ligado al transporte marítimo y terrestre. Por lo que respecta a los nautae es evidente su dedicación a la actividad mercantil de transporte de mercancías y/o personas. En cuanto a los otros dos grupos de profesionales: los caupones y los stabularii, es clara su relación con el transporte terrestre ${ }^{59}$, que

${ }^{58}$ Cf., entre otros, ARIAs Ramos, José, El transporte marítimo en el mundo romano, ob. cit., p. 52.

${ }^{59}$ Véase, Salazar Revuelta, M., La responsabilidad objetiva en el transporte marítimo y terrestre en Roma, ob. cit., p. 45. 
no parece que tuvo en Roma tanta importancia como el marítimo, como ya se ha dicho anteriormente. De esta forma, hay que considerar que «la decisión pretoria en torno al receptum se encuadra dentro de las numerosas providencias pretorias dirigidas a estimular el comercio» ${ }^{60}$. Además, el receptum al que nos estamos refiriendo, según los textos, va dirigido, en primer lugar, a los nautae, y se extiende después a los caupones y a los dueños de establos.

Concretamente, en el recipere del nauta, caupo et stabularius y dado que estos asumen una obligación en razón del ejercicio de su negocio, parece que el momento en el que se perfecciona el receptum es precisamente cuando las cosas para custodiar son cargadas en la nave, o introducidas en la posada o en la cuadra. Por ello, «la voluntad de recipere del porteador marítimo, del posadero y del dueño del establo se manifiesta en el hecho material mismo de tomar para su cuidado lo que los clientes les confían seguros del buen hacer profesional de aquellos» ${ }^{61}$.

De esta manera, el nauta que en el ejercicio de su actividad recibe las mercancías del cargador está obligado, en virtud de un edicto del pretor, a responder de toda pérdida o de todo daño sufrido por las mercancías recibidas (a menos que esta pérdida o daño no tengan por causa la falta de los empleados, de ellos mismos o en caso de absoluta fuerza mayor). Este edicto y la acción correspondiente han sido estudiados por Ulpiano en el libro 14 ad edictum, por Paulo en su libro 13 ad edictum, y por Gayo en el libro 5 ad edictum provinciale.

Veamos, en primer lugar, que determinados fragmentos de los textos de Ulpiano extraídos de sus comentarios figuran en el Digesto, sobre todo en el título especial consagrado a nuestra materia; se trata de Dig. 4,962, donde se establece que los navieros, mesoneros y estableros restituyan lo que asumieron bajo su custodia. En esta línea, el citado jurista nos da el texto del edicto en Dig. 4,9,1,pr., en el que dice el pretor: «Daré acción contra los navieros, mesoneros y estableros que no restituyan lo que de cualquier persona hubiesen asumido bajo su custodia», que ya se vio anteriormente.

Por lo que respecta a las causas que habrían sido tenidas en cuenta para la concesión de la actio ex recepto, algunos textos nos informan de por una

\footnotetext{
${ }^{60}$ Ibidem, p. 224.

${ }^{61}$ Sobre el particular, LóPEZ-AMOR, M., «Receptum argentarii. Receptum nautarum, cauponum, stabulariorum», en Derecho romano de obligaciones. Homenaje al Profesor Murga Gener, Madrid, 1994, p. 722.

${ }^{62}$ El texto de Ulpiano recogido en Dig. 4,9 lleva la siguiente rúbrica: Nautae, caupones, stabularii ut recepta restituant.

${ }^{63}$ Considera SAlazar Revuelta, M., La responsabilidad objetiva en el transporte marítimo y terrestre en Roma, ob. cit., pp. 229-230, que «está atestiguada la mala fama o reputación que tuvo el oficio del nauta: quizá por una mezcla entre los especiales peligros que conllevaba la navegación, el fin lucrativo que se perseguía con esta actividad y, especialmente, por la baja extracción social de las personas que constituían la tripulación de las naves (sobre todo, esclavos o libertos)».
} 
parte, según Ulpiano, citando a Pomponio (cf. Dig. 4,9,3,1) se trataría de sancionar la improbitas ${ }^{63}$ característica de este genus hominum que se dedican a la actividad mercantil marítima -nisi forte reprimendae improbitatis hoc genus hominum-, según el texto. Del mismo modo, se justifica la existencia de la actio derivada del receptum nautarum para evitar las ocasiones en que los comerciantes se pusieran de acuerdo con los ladrones para apoderarse de las cosas de sus clientes, según se dice en Dig. 4,9,1,1.

Esta razones, entre otras, motivaron que «el pretor tuviera que intervenir con la finalidad de proteger a los terceros contratantes, garantizando asimismo el normal desarrollo de las operaciones comerciales[...]» ${ }^{64}$. Por otro lado, una razón muy importante de carácter técnico-jurídica la proporciona Ulpiano en el citado texto contenido en Dig. 4,9,3,1, después de decir que en la locatio-conductio se responde por culpa y en el depósito tan solo por el dolo, en cambio, como consecuencia de este edicto que estableció el receptum al que nos estamos refiriendo, qui recepit se obliga en todo caso (omnímodo) y, además, aunque no haya intervenido culpa en la destrucción o daños causados en las cosas que se le entregaron, a no ser que damno fatali contingit.

Otro de los aspectos que se destaca precisamente en un texto de Gayo correspondiente al edicto provincial, contenido en Dig. 4,9,5 ${ }^{65}$ tiene relación con la naturaleza intrínseca de este tipo de responsabilidad; se dice en el texto que los citados profesionales están obligados por la razón de la custodia. El concepto central del edicto salvum fore recipere determina que el receptum nautarum (así como también el receptum cauponum y el stabulariorum) hace nacer precisamente una obligación de garantía. La obligación de restituir «sanas y salvas» las cosas que se entregaron a los citados profesionales expresa una extremada responsabilidad en cuanto que es indicativa de cualquier tipo de pérdida ${ }^{66}$.

Igualmente, Ulpiano (14 ed.) en el texto contenido en Dig. 4,9,3,1, en su parte final, se refiere a la verdadera naturaleza de la responsabilidad ex recepto, cuando dice: [...] At hoc edicto omnimodo qui recepit tenetur, etiamsi sine culpa eius res periit vel damnum datum est. El término omnímodo alude a una responsabilidad muy rigurosa y con la expresión sine culpa a

${ }^{64}$ Salazar Revuelta, M., «La responsabilidad objetiva ex recepto como fundamento jurídico de la protección a terceros en el Derecho comercial romano y su recepción en el Código civil español», ob. cit., p. 910.

${ }^{65}$ En el citado texto de Dig. 4,9,5, se establece lo siguiente: Nauta et caupo et stabularius mercedent accipiunt, non pro custodia, sed nauta ut traiiciat vectoras, caupo ut viatores manere in caupona patiatur, stabularius, ut permittat iumenta apud cum stabulari [...].

${ }^{66}$ Cf. LóPEZ-Amor, M., «Receptum argentarii. Receptum nautarum, cauponum, stabulariorum», ob. cit., p. 726.

${ }^{67}$ Salazar Revuelta, M., «La responsabilidad objetiva ex recepto como fundamento jurídico de la protección a terceros en el Derecho comercial romano y su recepción en el Código civil español», ob. cit., p. 902. 
una responsabilidad que podríamos calificar, en terminología moderna, de objetiva $^{67}$.

Con este tipo de receptum, además de responder por custodia, en su origen se tuvo que responder también por los daños causados en los supuestos de caso fortuito o de fuerza mayor. No obstante, conviene destacar que el rigor de la responsabilidad exigido a este tipo de profesionales y la gradual evolución del receptum nautarum (lo mismo del receptum cauponum et stabulariorum) llevó al pretor a introducir la posibilidad de neutralizar la actio ex recepto a través de una exceptio por hechos calificados de vis maior, cuando las cosas custodiadas perecían por accidente inevitable, por naufragio o asalto de piratas ${ }^{68}$.

De esta manera, las circunstancias mencionadas eximirían totalmente de la responsabilidad a qui recepit, pero también podría rehusarla o limitarla mediante una expresa declaración de descargo comunicada previamente al cliente y aceptada por este ${ }^{69}$. Por otro lado, una limitación de la responsabilidad al peculio podía tener lugar cuando un filius o un esclavo contrataban con el naviero sin el consentimiento del pater o del dueño. El texto de Ulpiano, en Dig. 4,9,3,3 presenta las dos hipótesis: en la primera el sometido a potestas se ha obligado con el consentimiento del padre o dueño, por lo tanto, estos últimos serán responsables en el caso de hurto y daños que sufran las mercancías; por el contrario, si actuaron sin el consentimiento del titular de la potestas, la responsabilidad se limita al peculio.

Conviene destacar, asimismo, que la exigencia de esta responsabilidad rigurosa solo surge como consecuencia de la actividad comercial que lleva a cabo el nauta y los demás profesionales a los que nos venimos refiriendo y no se exige fuera de su ámbito comercial, según se establece en Dig. 4,9,3,2. Por ello, el periculum que asumen quienes contraen el receptum con sus clientes y al que alude el texto en Dig. 4,9,3, pr., periculum ad eum pertine$r e$, sea considerado por la doctrina ${ }^{70}$ como riesgo empresarial.

${ }^{68}$ Véase el texto de Ulpiano en el libro 14 de los comentarios al Edicto, en Dig. 4,9,3,1, donde dice, entre otras cosas [...] At hoc Edicto omnimodo, qui recepit, tenetur, etiamsi sine culpa eius res periit, vel damnum datum est, nisi si quid damno fatali contingit. Inde Labeo scribit, si quid naufragio, aut per vim piratarum perierit, non esse iniquum exceptionem ei dari. Idem erit dicendum, et si in stabulo, aut in caupona vis maior contigerit.

69 Vid., entre otros, Salazar Revuelta, M., «La responsabilidad objetiva ex recepto como fundamento jurídico de la protección a terceros en el Derecho comercial romano y su recepción en el Código civil español», ob. cit., p. 903; GuARINO, A., Diritto privato romano. 11. ${ }^{a}$ ed., Napoli, 1997, pp. 967-968.

${ }^{70}$ SERRAO, F., Impresa e responsabilità a Roma nell'età commerciale. Forme giuridiche di una economia mondo, Pisa, 1989, pp. 102-103; Idem, «La responsabilità per fatto altrui in Diritto romano», en BIDR, 66 (1963), p. 26. El citado autor se refiere al «riesgo de empresa» y más en general según el «riesgo de actividad», ibidem; CERAMI, P., Di PorTo, A., Petrucci, A., Diritto Commerciale Romano. Profilo Storico, 2. a ed., Torino, 2004, p. 276. 
Ahora bien, en cuanto al fundamento de la responsabilidad ex recepto la doctrina mas reciente considera que no descansa simplemente en un riesgo de empresa ${ }^{71}$, sino que se puede explicar también por la disponibilidad de los bienes del cliente por parte del profesional (nauta, caupo o stabularius) como consecuencia de la actividad profesional que desempeña ${ }^{72}$.

Otro aspecto a tener en cuenta tiene relación con las cosas que son objeto de reclamación, para que se produzca este tipo de responsabilidad:[...] quamcumque rem, sive mercem receperint, según el texto de Ulpiano contenido en Dig. 4,9,1,6. Además, el compromiso asumido lo era frente a los clientes. No obstante, poco importaba que las cosas que debían ser devueltas fuesen propiedad de los clientes o de terceros, Dig. 4,9,1,7, y, además, como ya se ha dicho también anteriormente, la responsabilidad del naviero tiene lugar cuando se producen actos por terceras personas; indican los textos a este respecto que responde no solamente de los empleados, sino también de los hechos de los pasajeros ${ }^{73}$.

En definitiva, en los pasajes citados del Digesto se puede apreciar la responsabilidad de los nautae que nace, persigue la restitución de las mercancías entregadas a estos, hace frente a los actos del propio naviero, de su personal, y aun de extraños, y no exige intervención de culpa; pero ha de originarse por actos profesionales (salvo en la esfera penal) y no cesa siquiera en el supuesto de caso fortuito, aunque sí cesa en el supuesto de que se haya producido un naufragio, asalto de piratas o una circunstancia de fuerza mayor; tampoco responde el naviero cuando este y el pasajero convinieron en ello ${ }^{74}$.

Finalmente, y a modo de resumen, presentamos algunas otras consideraciones que atañen a los recursos procesales descritos -entiéndase las actiones penales y la actio recepticia dirigidas contra los profesionales a los que nos venimos refiriendo-. La opinión prevalente ${ }^{75}$ considera que las dos

${ }^{71} \mathrm{Cf}$. SERRAO, F., Impresa e responsabilità a Roma nell'età commerciale. Forme giuridiche di una economia mondo, ob. cit., pp. 103-ss.; FerCIA, R., Criteri di responsabilità dell'exercitor. Modellil culturali dell'atribuzione di rischio e «regime» della nossalità nelle azioni penali in factum contra nautas, caupones et stabularios, Torino, 2002, pp. 10-ss. nt. 19; pp. 48-ss., 218-ss.

${ }_{72}$ Vid. FerCIA, R., Criteri di responsabilità dell'exercitor, ob. cit., pp. 218-221.

${ }^{73} \mathrm{Cf}$. Dig. 4,9,1,8: [...] Et factum non solum nautarum praestare debere, sed et vectorum. Asimismo, en Dig. 4,9,2, el texto de Gayo, correspondiente al Edicto provincial, en el libro 5, establece esto: Sicut et caupo viatorum.

${ }^{74} \mathrm{Cf}$. Dig. 4,9,7, pr., donde se establece al respecto: [...] Item si praedixerit, ut unusquisque vectorum res suas servet, neque damnum se praestiturum, et consenserint vectores praedictioni, non convenitur.

${ }^{75}$ Zimmermann, The Law of Obligations. Roman Foundations of the Civilian Tradition, Oxford, 1996, p. 517. FoLDI, A., «Anmerkungen zum Zusammenhang zwischen der Haftung ex recepto nautarum,cauponum, stabulariorum und der Haftung für custodia», en RIDA 40 (1993), pp. 276-ss. 
acciones penales habían precedido a la actio derivada del receptum nautarum. Una vez introducida la actio recepticia, los tres recursos coexistieron durante la etapa comercial romana ${ }^{76}$. Las acciones penales in factum adversus nautas, caupones et stabularios, a través de su condemnatio al duplum, implican un incremento de los costes del periculum «de ahí que el pretor interviniera con la actio de recepto, con la finalidad de garantizar el buen equilibrio económico de las partes, dejando a su arbitrio la posibilidad de pactar el receptum. En consecuencia estas razones de utilidad justifican sobradamente la intervención pretoria» ${ }^{77}$.

Por otro lado, conviene destacar que el tipo de responsabilidad que se exige al nauta constituye un instrumento muy apropiado a las exigencias de la vida económica del mundo romano de la época republicana y del Imperio. El criterio subjetivo de culpa está fuera de la responsabilidad del nauta por los daños que sufran las cosas transportadas: «se trata verdaderamente de una responsabilidad objetiva, que encuentra en el sistema procesal romano la más idónea expresión en un medio, como la actio in factum, extraño a la distinción del fundamento contractual o delictivo de la responsabilidad» ${ }^{78}$. Ahora bien, como venimos diciendo a lo largo de las presentes líneas, en época posterior, se reconduce este tipo de responsabilidad a una presunción de culpa, elaborada bajo el criterio de culpa in eligendo; de este modo, «la responsabilidad objetiva que nace de las acciones penales in factum se insertará en la categoría de los quasi ex maleficio; en tanto que la responsabilidad ex recepto vendrá a considerarse un tipo particular de la diligentia exactissi$m a$, con su único límite en el casus maior» ${ }^{79}$.

Además de las actiones descritas que nos presentan supuestos de responsabilidad objetiva, ya el primitivo Derecho romano había regulado el régimen de responsabilidad objetiva que encuentra su expresión en las acciones noxales contra el pater y el dominus basándose, sobre todo, en un tipo de responsabilidad por los daños ocurridos en los límites de su esfera jurídica como consecuencia de las actividades llevadas a cabo por personas

\footnotetext{
${ }^{76}$ Cerami, P., Di Porto, A., Petrucci, A., Diritto Commerciale Romano, ob. cit., p. 300.

77 Salazar Revuelta, M., La responsabilidad objetiva en el transporte marítimo y terrestre en Roma, ob. cit., p. 231.

${ }^{78}$ SARGENTI, M., «Osservazioni sulla responsabilità dell'exercitor navis in Diritto romano», en Studi in memoria di Emilio Albertario. Vol. 1. ${ }^{\circ}$, Milano, 1953, pp. 579-580.

79 Salazar Revuelta, M., La responsabilidad objetiva en el transporte marítimo y terrestre en Roma, ob. cit., p. 240.

${ }^{80}$ SARGENTI, M., «Osservazioni sulla responsabilità dell'exercitor navis in Diritto romano», ob. cit, p. 579.
} 
que tienen incapacidad tanto jurídica como patrimonial (filiifamilias y esclavos $)^{80}$.

\section{La regulación en las Siete Partidas}

Después del estudio de los textos romanos relativos a la responsabilidad de los nautae en el ejercicio de su profesión, nos referimos a continuación en el presente apartado a algunas disposiciones contenidas en el texto alfonsino de las Partidas que tienen relación del mismo modo con las actuaciones de los nautae y su responsabilidad como consecuencia de sus actividades en el tráfico marítimo.

Como es sabido, uno de los textos más representativos de la recepción del Derecho común en Castilla son las Siete Partidas, y en materia de responsabilidad del porteador, al igual que en otras muchos supuestos, adopta la doctrina romana; de esta manera, el porteador responde siempre, salvo que pueda probar alguna circunstancia de fuerza mayor ${ }^{81}$. También es conocido que la influencia del Derecho romano es particularmente intensa sobre todo en el campo del Derecho privado y del penal en los textos medievales, y así el texto legal más importante de Alfonso X el Sabio se refiere a la materia objeto de nuestro estudio en diferentes sedes de este.

En primer lugar, el criterio de responsabilidad por culpa se menciona en la P. 5,8,13, donde se establece en la rúbrica lo siguiente: Como el que da afletada su naue a otro deue pechar el daño de las mercaderías, é de las otras cosas que se perdieren por su culpa. Concretamente, se establece en el citado texto de la ley que: si la naue peligrasse, o se quebrantasse, entonces el daño, e la perdida que acaescies en aquellas mercaderias pertenescen al señor de la naue [...].

${ }^{81}$ Respecto al cargador, según dice Morán MARTín, R., Historia del Derecho privado, penal y procesal, Madrid, 2002, p. 315, «lo más significativo es que corre con el riesgo de las cosas transportadas, siempre que no provenga de culpa o dolo del porteador».

${ }^{82}$ El texto de la Partida 5,8,26, bajo la rúbrica: Como los ostaleros e los aluergadores, é los marineros son tenudos de pechar las cosas que perdieren en sus casas e en sus nauios aquellos que ay rescibieren, establece a continuación lo siguiente .- Cavalleros, o mercadores: o otros omes que van camino, acaesce muchas vegadas, que han de posar, en casa de los ostaleros, e en las tauernas, de manera, que han de dar sus cosas a guardar a aquellos que y fallaren, fiandose en ellos, sin testigos, é sin otro recabdo ninguno: e otro sí los que han a entrar sobre mar, meten sus cosas en las naues en essa misma manera fiandose en los marineros: e porque en cada una destas maneras de omes acesce muchas vegadas. Que ay algunos que son muy desleales, e fazen muy grandes daños, e maldades, en aquellos que se confian: por ende conuiene, que la su maldad sea refrenada con miedo de pena. Onde mandamos que todas las cosas, que los omes que van camino por tierra, o por mar metiren en las casas de los ostaleros, o de los tauerneros, o en los nauíos, que andan por mar o por los rios, aquellas que fueren y metidas, con sabiduria de los señores de los ostales, o de las tauernas: o de las naues: o de aquellos que estouieren y, en lugardellos, que las guarden de guisa que se non se pierdan, nin se menoscaben: e si se perdiessen por su negligencia, o por engaño que ellos fiziessen: o por otra en su culpa, o si las furtassen algunos de los omes 
El criterio de responsabilidad objetiva lo vemos recogido en la misma Partida y en el mismo Título, concretamente en P. 5,8,2682, donde se refiere a la responsabilidad de los navieros, bajo la siguiente rúbrica: Como los ostaleros é los aluergadores, é los marineros son tenudos de pechar las cosas que perdieren en sus casas é en sus nauios aquellos que ay rescibieren. En primer lugar, podemos observar en el texto que se transcribe a pie de página que la citada disposición alude a las tres clases de profesionales -los ostaleros é los aluergadores, é los marineros-que hemos visto reiteradamente en los textos romanos. Del mismo modo, numerosos aspectos correspondientes a la citada ley 26 tienen su base en la regulación romana. Veamos, por ejemplo, lo relativo a la responsabilidad de los navieros que trasladan las mercancías por mar o por río, cuando se establece como dice el texto: e otro sí los que han a entrar sobre mar, meten sus cosas en las naues en essa misma manera fiándose en los marineros: e porque en cada una destas maneras de omes acesce muchas vegadas.

$\mathrm{Al}$ igual que hemos visto en los textos de la época romana, en la ley alfonsina se justifica la exigencia de la responsabilidad rigurosa a los profesionales que cita el texto debido a que ay algunos que son muy desleales, $e$ fazen muy grandes daños, e maldades, en aquellos que se confian: por ende conuiene, que la su maldad sea refrenada con miedo de pena.

Del mismo modo, como también se ha dicho, en la regulación romana se equipara la introducción de las cosas al recibo formal de ellas: rerum quae illatae sunt; por lo que respecta a la ley citada del texto alfonsino, esta se manifiesta en los siguientes términos: [...] Aquellas que fueren y metidas con sabiduria de los señores de los ostales o de las tauernas: o de las naues: o de aquellos que estouieren y, en lugar dellos, que las guarden, de guisa que se non pierdan, nin se menoscaben. Por otro lado, le exige responsabilidad al naviero, en los casos de pérdida o daños ocasionados en las cosas, no solo

que vienen con ellos, entonces ellos serian tenudos de les pechar todo quanto perdiessen, o menoscabassen. Ca guisada cosa es, que pues que fian en ellos, los cuerpos, e los aueres, que los guarden lealmente, a todo su poder: de guisa que non resciban mal, nin daño. E lo que diximos en esta ley, entiendese, de los ostaleros, e de los tauerneros, e de los señores de los nauios, que vsan publicamente a recebir los omes tomando dellos ostalaje, o loguero. E en esta misma manera, dezimos, que son tenudos de los guardar estos sobredichos si los resciben por amor, non tomando dellos ninguna cosa, fueras ende en casos señalados. El primero es, si ante que lo reciba le dize, que guarde bien sus cosas que non quiere el ser tenudo de las pechar si se perdieren. El segundo es si le mostrare ante que lo rescibiesse, arca, o casa, e le dize: si aui queredes estar, meted en esta casa, o en esta arca, vuestras, cosas, e tomad la llaue della e guardadlas bien. El tercero es, si se perdiessen las cosas por alguna ocasion, que auiniesse: assi como fuego que las quemasse, o por auenidas de rios: o si se derribasse la casa: o peligrasse la naue: o se perdiessen por fuerza de enemigos. Ca perdiendose las cosas por alguna destas maneras sobredichas, que non auiniesse, por engaño, o por su culpa dellos, entonce non serian tenudos de las pechar. 
en el supuesto de haber actuado con culpa o conducta dolosa, sino también: o por otra en su culpa, o si las furtassen algunos de los omes que vienen con ellos.

Otro de los aspectos a destacar en la mencionada ley tiene relación con una serie de circunstancias que eximen de responsabilidad a los citados profesionales (ostaleros, tauerneros y nauieros), siempre que no haya engaño o culpa por su parte. Uno de los supuestos que se menciona en primer lugar y que hace cesar la responsabilidad del naviero tiene lugar cuando este y el viajero convinieron en ello -si ante que lo reciba le dize, que guarde bien sus cosas que non quiere el ser tenudo de las pechar si se perdieren-siguiendo lo ya establecido en el Derecho romano ${ }^{83}$. Más adelante, se refiere el texto a determinadas circunstancias ajenas completamente a la voluntad del naviero, si peligrasse la naue: o se perdiessen por fuerza de enemigos, en estos casos mencionados tampoco hay responsabilidad, según se establece en la ley alfonsina. Por lo tanto, si se perdiesen las cosas transportadas, por alguna destas maneras sobredichas, que non auiniesse, por engaño, o por su culpa dellos, entonce non serian tenudos de las pechar. Finalmente, destacamos de la citada ley otro aspecto que ya se ha visto también en los textos romanos, cuando dice que se va a exigir el mismo tipo de responsabilidad a los nauieros (así como también a los ostaleros y tauerneros), si los resciben por amor, non tomando dellos ninguna cosa, según dice el texto alfonsino.

De nuevo, en la P. 5,9,9 se le puede pedir responsabilidad al naviero. Se responsabiliza a los gobernadores del navío si se pierden o sufren deterioros las mercancías que en él se transportan habiendo actuado de forma temeraria y contra la voluntad de los dueños de las mercancías. Del mismo modo, es responsable si el dueño del barco pone al frente de este a gobernantes poco conocedores del oficio.

En otra sede del texto alfonsino, se regulan asimismo aspectos relacionados con las mercancías que se dejan en la aduana. Nos estamos refiriendo a la Partida 7 cuyo contenido es materia de derecho penal; pues bien, los posibles hurtos que se produzcan en las mercancías que son dejadas en la aduana, antes o después de ser trasladadas por mar, se mencionan en el título 14 de la citada Partida, que tiene relación precisamente con los furtos en general. Concretamente la Partida 7,14,7, lleva la siguiente rúbrica: Como aquel que tiene el ostalaje en su casa, e los almoxarifes que guardan el aduana, e los otros que guardan el alfondiga del pan son tenudos de pechar las cosas que furtan en cada uno destos lugares.

La citada ley, después de referirse a la responsabilidad del hostelero por el hurto que pueda cometer él mismo, u otro cualquiera por su mandato o por su consejo, se establece que sea sancionado con la pena del hurto. Si el delito es cometido por algún hombre que estuviese a soldada, deberá pagar el

${ }^{83}$ Cf. el texto recogido en Dig. 4,9,7,pr. 
doble de la cosa hurtada y, según dice además la Ley, maguer non fuesse furtada por su mandado, nin por su consejo. Le responsabiliza la citada ley por contratar para su establecimiento a personas malhechoras.

Se contempla asimismo el supuesto de que el furto sea cometido por un siervo y se le da en este caso al dueño la posibilidad de elegir entre el pago del doble del valor de lo hurtado o la entrega del siervo. Se establece también en la misma disposición que si el hurto se ha cometido por un extraño, el dueño del hospedaje no tiene ninguna responsabilidad. Lo que se ha dicho sobre el dueño del hospedaje es asimismo extensible a los dueños de establos y de naves: en su casa, o en su establia, o en su naue recibiendo un ome a otros, con sus bestias, o con sus cosas [...]. De ahí que termine la mencionada ley estableciendo lo siguiente: [...] Otrosí dezimos que el almoxarife es tenudo de dar recabdo de toda la mercaduria que se mete, e se pone en el aduana.

\section{Responsabilidad del porteador por los daños producidos por la muer- te o lesiones del viajero en el Derecho actual}

\section{Consideraciones generales acerca del contrato de transporte}

El contrato de transporte en la actualidad es «no solo el aspecto de Derecho privado a que se refieren los Códigos civil y de comercio, sino que lleva consigo una consideración administrativa, internacional, social y económica que oscurece la regulación clásica privatista, si bien esta regulación no deja de ser la base sobre la que descansan las otras facetas» ${ }^{84}$. Rigen el contrato de transporte las normas del Código civil y las del Código de comercio, que forman el derecho común para toda clase de transportes, si bien se anteponen la aplicación de las normas del segundo como más específicas que son ${ }^{85}$.

Por otro lado, están las normas administrativas; conviene destacar que la historia del Derecho administrativo, en gran medida, consiste en la búsqueda de títulos jurídicos que expliquen y justifiquen la intervención de los poderes públicos en la actividad de los particulares. Uno de los primeros títulos de intervención fue la paz de los caminos. «La paz pública en los caminos, la seguridad en los transportes, la posibilidad de desplazarse de un lugar

${ }^{84}$ AA. VV. Tratado de Derecho civil, 4. Teoría y práctica. Coordinador I. Sierra Gil de La Cuesta, Barcelona, 2003, p. 393.

${ }^{85}$ Ibidem, p. 394.

${ }^{86}$ Blanquer, D., Derecho del Turismo, Valencia, 1999, p. 337. Según el citado autor, «la importancia de esa intervención fue capital no solo para peregrinaciones como la del camino de Santiago, sino para todo el tráfico económico entre las ciudades que empiezan a surgir y configurarse en el tránsito desde la Edad Media al Renacimiento», cf. ibidem. 
a otro sin el riesgo de encontrarse con bandidos y salteadores de caminos, fue una de las primeras aspiraciones que los particulares reclamaron a los Poderes Públicos» ${ }^{86}$.

En cuanto a la regulación del transporte en el Código civil, solo tres artículos dedica a este contrato (1601, 1602 y 1603). Además, como se deduce de su colocación, lo considera como una variedad de arrendamiento de obra bajo la rúbrica «de los transportes por agua y tierra, tanto de personas como de cosas». Los autores ponen de relieve la parquedad de las normas del Código civil en la regulación de este contrato, limitadas exclusivamente a determinar la responsabilidad de los conductores en cuanto a la guarda y conservación de las cosas transportadas y por daño o pérdida de estas, y a remitirse a las normas del Código de comercio y a las leyes y reglamentos especiales $^{87}$.

La escasa regulación del Código civil puede explicarse porque ya en la época de su publicación las actividades de transporte estaban vinculadas a la organización profesional ${ }^{88}$. Por lo tanto «estos contratos en su mayor parte quedarán sujetos: a las normas mercantiles, puesto que la mayoría de los transportes tienen naturaleza mercantil; y a las normas administrativas, por cuanto la conducción de personas y cosas, tanto si se realizan por tierra como por mar o por aire, afectan no solo a los contratantes, sino al público en general, por razón principalmente de la utilización de los medios de transporte cuya ordenación incumbe en gran parte al Derecho administrativo» ${ }^{89}$.

Por otro lado, el contenido de la escasa regulación del Código civil no se halla en consonancia con la rúbrica de la sección en que se hallan encuadrados, que se refiere a los transportes «tanto de personas como de cosas». Es de notar que, a pesar de la generalidad de la citada rúbrica, los artículos que la integran se refieren al transporte de cosas sin mencionar el de personas. Del mismo modo, aunque es de apreciar la amplitud de la rúbrica de esta sección, no se contiene en ella norma alguna sobre la definición del contrato, sus elementos personales, ni se refiere a los derechos y obligaciones que de él nacen para las partes ${ }^{90}$. De los diversos elementos personales que intervienen en la ejecución del transporte, el Código alude solo al transportista con la denominación de conductor y surge para él la obligación de traslado (per-

${ }^{87}$ LuCas Fernández, F., Comentarios al Código civil y Compilaciones forales. Dirigidos por M. Albaladejo. Tomo XX. Vol. 2, p. 486.

${ }^{88}$ González Poveda, P., Comentario del Código civil. Coordinador, Sierra Gil de la Cuesta. Tomo 7, Madrid, 2000, p. 691.

${ }^{89}$ LuCAs Fernández, F., Comentarios al Código civil y Compilaciones forales, ob. cit., p. 486.

${ }^{90}$ Entre otros, véase, GonzÁlez PovedA, P., Comentario del Código civil, ob. cit., p. 690.

${ }^{91}$ Ibidem, p. 691. 
sonas o cosas), además de la obligación ex lege de guarda y custodia de las cosas o efectos transportados a la que se refiere el art. 1602 citado $^{91}$.

Un aspecto de gran interés en el contrato de transporte tiene relación con la responsabilidad de los porteadores y por ello conviene destacar en primer lugar lo siguiente: para que una cosa sea transportada es menester entregarla al porteador o conductor, como dice el Código. De esta manera, desde que la cosa se entrega por el cargador o remitente, hasta que la recibe el consignatario, el conductor la tiene en su poder, como condición precisa del transporte y está obligado a conservarla y guardarla, y es de razón natural que responda de ella ${ }^{92}$.

Asimismo se le responsabiliza al porteador con un régimen severo (art. 1602) de la pérdida y averías que sufran las cosas. La pérdida equivale a falta de entrega de la cosa, cualquiera que sea la causa jurídica o material que la origine. Además, la pérdida puede ser total o parcial. Por otro lado, la avería presupone que las cosas han llegado a su destinatario pero que presentan, en todo o en parte, alteraciones en sus cualidades, tanto intrínsecas como extrínsecas, de tal forma que resulta modificado el estado en que los géneros fueron entregados al porteador. Ahora bien, el mismo artículo al que nos estamos refiriendo establece que los conductores pueden liberarse de responsabilidad si prueban que la pérdida o la avería ha sido debida a caso fortuito o fuerza mayor.

En el Código de comercio, la regulación de los transportes terrestres se halla en los artículos 349 a 379 y la de los marítimos, en los artículos 652 a 718. Son conocidas las críticas de los mercantilistas al art. 349 que pretende distinguir los transportes mercantiles de los civiles, cuando la realidad demuestra que el contrato es solo uno: «el transporte de derecho privado con matices distintos de carácter marginal (administrativos, fiscales, de orden público, etc.), por ello, y según la experiencia de otros países (Suiza e Italia, por ejemplo) consideran algunos autores que parece indicado que este contrato debería incluirse con regulación unitaria en el Código civil, actualizando los viejos preceptos de ambos Códigos (Civil y de Comercio)» ${ }^{93}$.

Por lo que respecta a la responsabilidad, de no existir pacto en contrario, los objetos porteados viajan «a riesgo y ventura del cargador»y, en consecuencia, «serán de cuenta y riesgo del cargador todos los daños y menoscabos que experimenten los géneros durante el transporte por caso fortuito, fuerza mayor o naturaleza y vicio propio de las cosas» incumbiendo al porteador la prueba de esos accidentes (art. 361). Esta regla, coincidente con la

${ }^{92}$ Sobre el particular, cf. Manresa y Navarro, J. M., Comentarios al Código civil español. Tomo X, Madrid, 1908, p. 773.

${ }^{93}$ AA.VV. Tratado de Derecho civil. 4. Teoría y práctica. Coordinador, I. Sierra Gil de la Cuesta, ob. cit., p. 396. 
establecida en el Código civil (art. 1602), aunque parezca a primera vista muy favorable para el porteador, en realidad no lo es por las dos razones siguientes: porque le impone la carga de la prueba, por lo general bastante dificultosa, y, por otra parte, porque viene templada con lo que se establece en el artículo siguiente que hace responsable al porteador de los daños y menoscabo de las cosas porteadas, «si se probare en su contra que ocurrieron por su negligencia o por haber dejado de tomar las precauciones que el uso tiene adoptadas entre personas diligentes» $\left(\right.$ art. 362) ${ }^{94}$. De esta forma la cuestión de la carga de los riesgos se reducirá siempre en la práctica a una pura cuestión de prueba sobre la causa del accidente dañoso ${ }^{95}$.

En cuanto a la responsabilidad en el transporte de personas es evidente la diferencia con el transporte de cosas. «A las peculiaridades técnicas del trasporte de personas, derivadas del hecho de transportarse un ser viviente, que vigila y colabora continuamente en el transporte, se corresponden especiales formas de responsabilidad por incumplimiento del transporte. La muerte o el daño, sufridos por la persona del viajero no pueden ser equiparados a la pérdida o a la avería de una mercancía ${ }^{96}$. Por ello no son aplicables los preceptos del Código de comercio (arts. 363, 368 y 371) que se refieren a pérdidas de las cosas.

La responsabilidad del porteador es la cuestión fundamental del régimen del transporte de personas, por ello, en las siguientes líneas nos vamos a centrar en la responsabilidad que le corresponde al porteador como consecuencia de los daños con resultado de muerte o lesiones ocasionados a las personas que han contratado con un medio de transporte.

\section{La imputación del daño: del sistema de responsabilidad por culpa a la responsabilidad objetiva}

La moderna elaboración de la noción de responsabilidad objetiva por la dogmática civilística hunde sus raíces más profundas en las fuentes romanas, como se ha puesto de manifiesto en los epígrafes correspondientes; en concreto, por lo que se refiere a la responsabilidad de determinados empresarios es evidente «la supervivencia de los criterios objetivos como el del riesgo empresarial y los principios aparejados a este tipo de responsabilidad, como el de la buena fe objetiva, que todavía inspiran los ordenamientos jurídicos modernos, sobre todo por lo que se refiere al derecho de los consumidores ${ }^{97}$.

${ }^{94}$ Sobre el particular, véase URíA, R., Derecho mercantil. Vigésima edición. Madrid, 1993, p. 657.

${ }^{95}$ Ibidem, p. 657.

${ }^{96}$ Entre otros, véase GaRrigues, J., Curso de derecho mercantil, Madrid, 1939, pp. 234 235.

97 Salazar Revuelta, M., La responsabilidad objetiva en el transporte marítimo y terrestre en Roma, ob. cit., p. 30. 
Como se ha dicho al tratar el tema de la responsabilidad del nauta en la época del Derecho romano, el desarrollo a gran escala del tráfico comercial marítimo iba a plantear todo tipo de problemas jurídicos y para ello se concedieron una serie de remedios legales a favor de los particulares. Es evidente que en la actualidad la prestación de los servicios de transporte a enormes contingentes de personas, así como el continuo tráfico de mercancías, hace necesaria la puesta a disposición de los usuarios de una serie de recursos jurídicos como defensa de sus derechos frente al transportis$\mathrm{ta}^{98}$.

Si nos centramos en el transporte de personas, conviene destacar que en la regulación tradicional se aplican los preceptos civiles sobre responsabilidad contractual por culpa, tanto en el caso de muerte o accidente como en el de retraso. No obstante, en las modernas regulaciones en materia de transportes -terrestre, marítimo y aéreo- la responsabilidad objetiva frente al porteador se va imponiendo, tanto en el ámbito doctrinal, así como en el jurisprudencial. La responsabilidad objetiva tiene la misma finalidad de resarcir los daños a quien no tiene obligación de soportarlos, pero a través de un mecanismo completamente distinto del criterio tradicional de responsabilidad por culpa ${ }^{99}$; el porteador solo puede exonerarse de responsabilidad por dos razones: la culpa de la propia víctima o la fuerza mayor. La jurisprudencia ha basado esta técnica en la creación de un riesgo, que finalmente produce el daño ${ }^{100}$.

Este tipo de responsabilidad, que es independiente de la conducta del sujeto, es decir, sin intervención de ningún elemento subjetivo de responsabilidad de dolo o culpa, lo hemos visto en el Derecho romano al referirnos a determinados profesionales (nautae, caupones y stabularii), por un lado, en los supuestos del ejercicio contra ellos de ciertas actiones in factum; por otro lado, el mismo sistema de responsabilidad objetiva se ha mencionado asimismo al tratar del edicto que estableció el receptum; según los textos, qui recepit se obliga en todo caso (omnímodo) y además, aunque no haya intervenido culpa en la destrucción o daños causados en las cosas que se le entregaron, a no ser que damno fatali contingit.

${ }^{98}$ Como es sabido existen dos grandes sistemas para atribuir a una persona la obligación de reparar el daño producido: o la culpa o la responsabilidad objetiva y ambos sistemas no se excluyen en las modernas legislaciones, sino que conviven.

${ }^{99}$ Sobre el particular, entre otros, véase RocA, E., Derecho de daños. Textos y materiales. 2. ${ }^{\text {a }}$ ed., Valencia, 1998, p. 211.

${ }^{100}$ Cf. la STS de 31 de enero 1992 en la que se dice que «la denominada responsabilidad por riesgo viene a significar que las consecuencias dañosas de ciertas actividades o conductas, aun lícitas y permitidas, deben recaer sobre el que ha creado un peligro para tercero, doctrina que, llevada a sus últimas consecuencias, condena a la pura objetivación del daño y desemboca en la obligación de responder por el peligro puesto por sí mismo [...]». 
Además, el criterio de responsabilidad objetiva, es objeto de recepción en algunas leyes de la época medieval, como se ha visto en las Partidas, y es tenido en cuenta en el Derecho actual en determinadas leyes que regulan los daños ocasionados a los viajeros que han contratado con el porteador. Precisamente, a propósito de la citada responsabilidad objetiva, hace ya unos cuantos años decía Sánchez Gamborino, en un artículo acerca de la Ley de Navegación Aérea de 1960, que «el criterio de responsabilidad objetiva o absoluta habrá de imponerse en los transportes por las diferentes vías como más consecuente con la seguridad contractual, al interés público de la actividad de los transportes y a la equidad» ${ }^{101}$. En la actualidad existen diferentes tipos legales de responsabilidad objetiva y nuestro propósito en las siguientes líneas es referirnos a aquellos que están previstos en algunas normas relacionadas con los transportes de viajeros.

\section{Responsabilidad por los daños ocasionados a las personas en el transpor- te terrestre}

El transporte de viajeros por vía terrestre puede realizarse tanto por ferrocarril como mediante vehículos por carretera. «La circunstancia capital de que la prestación del porteador se refiera en este transporte a una persona humana atribuye a este contrato especiales características frente al transporte de cosas: es evidente que en él no cabe hablar de entrega, ni al comienzo ni al final del contrato, y no existe nunca ese tercer elemento de carácter personal que es el consignatario» ${ }^{102}$. En cuanto a la responsabilidad del porteador por daños, al no poder aplicarse al viajero los preceptos relativos al transporte de cosas, regirán los preceptos comunes sobre culpa y responsabilidad contractual $^{103}$, conforme al criterio tradicional.

En esta clase de transporte, hay que tener en cuenta además que el ejercicio de la acción de responsabilidad civil contractual se fundamenta princi-

101 SÁnchez Gamborino, F. M., «El sistema de responsabilidad objetiva de la Ley de Navegación Aérea y su posible extensión a los transportes por todas las vías», en Revista de Derecho Mercantil. Vol. 39. N. ${ }^{\text {7 } 75, ~ 1960, ~ p . ~} 154$.

${ }^{102}$ Entre otros, véase URÍA, R., Derecho mercantil, ob. cit., p, 661.

${ }^{103}$ Véase, AA.VV., Tratado de derecho civil. Teoría y práctica. Tomo IV. Derecho de obligaciones, Barcelona, 2003, p, 407; Broseta Pont, M. y Martínez SAnZ, F., Manual de Derecho mercantil. 13. ${ }^{a}$ ed. Vol. II, Madrid, 2006, p. 171; SÁNCHEZ CALERO, F., Instituciones de Derecho mercantil. Vol. II. 25. ${ }^{\text {a }}$ ed., Madrid, 2003, p. 375. Si nos referimos al ámbito jurisprudencial, SÁNCHEZ GAMBORINO, «Responsabilidad del porteador por daños a los viajeros en sus personas», RDM, 1958, n. ${ }^{\circ} 70$, pp. 339-ss., pone de manifiesto las vacilaciones iniciales del Tribunal Supremo, que comenzó calificando la responsabilidad del transportista por lesiones o muerte de los viajeros como responsabilidad extracontractual, hasta la sentencia de 4 de julio de 1953, en la que se inclinó por la doctrina contractualista. 
palmente en la adquisición del billete por el viajero por el que se acredita la existencia de un previo contrato de transporte que le une con el porteador y por el que este queda obligado a transportarlo de un lugar a otro de forma que llegue incólume a su destino ${ }^{104}$. Del mismo modo, para que se produzca la responsabilidad civil es preciso que exista un criterio que permita imputar de forma dolosa o culposa dicha responsabilidad al transportista tanto por sus actos propios como por los de sus dependientes (art. 1596 del Código (ivil) ${ }^{105}$.

No obstante, este sistema de responsabilidad por culpa puede resultar corregido a través de la aplicación de las normas dirigidas a la protección de los consumidores y usuarios ${ }^{106}$. El viajero en posesión del billete es un usuario que tiene derecho a ser indemnizado por los daños y perjuicios ocasionados por el porteador y se puede considerar que le es de aplicación la actual normativa para la defensa de los consumidores y usuarios ${ }^{107}$; uno de sus derechos básicos tiene relación con la protección contra los riesgos que puedan afectar a su salud o seguridad (cf. art. 8); por otra parte, en el art. 107 donde se refiere al ámbito de aplicación de los contratos celebrados fuera de

${ }^{104}$ En fechas más recientes, la STS de 31 de mayo de 1985, se pronunció sobre un supuesto de muerte de varios viajeros como consecuencia del derrape y posterior caída a un barranco del vehículo en el que viajaban. El transportista interpuso recurso de casación alegando la incorrecta aplicación por la Audiencia del artículo 1214 Código civil. El Tribunal desestimó el recurso. En el Considerando Tercero afirma que «no discutida la existencia de un contrato de transporte terrestre de viajeros que vincula a las partes y surgiendo del mismo como obligación principal del porteador el traslado del pasajero desde el punto de partida al del destino, es manifiesto que el incumplimiento de tal deber, y las consecuencias dañosas para la vida o la integridad física del viajero que de tal incumplimiento se deriven, deben serle imputables (al transportista) en tanto no acredite que la falta de cumplimiento se debió a caso fortuito o fuerza mayor [...]».

${ }^{105}$ Cf. la STS de 22 de junio de 1989 que ha sido comentada por GordiLlo, J., «Comentario a la STS de 22 de junio de 1989», CCJC, núm. 20, 1989, pp. 533-ss. En la citada sentencia se le impone responsabilidad a la empresa de transporte por el incumplimiento culpable de los empleados que omiten una adecuada revisión del estado de los vehículos.

${ }^{106}$ Sobre el particular, cf. Rojo Álvarez-MANZANEDA, C., La responsabilidad civil por daños causados por servicios defectuosos. Daños a la salud y seguridad de las personas, ob. cit., p. 388.

${ }^{107}$ Nos referimos al Real Decreto Legislativo 1/2007, de 16 de noviembre, por el que se aprueba el texto refundido de la Ley General para la Defensa de los Consumidores y Usuarios y otras leyes complementarias.

${ }^{108} \mathrm{El}$ art. 148, que lleva la rúbrica Régimen especial de responsabilidad, establece seguidamente:

Se responderá de los daños originados en el correcto uso de los servicios, cuando por su propia naturaleza, o por estar así reglamentariamente establecido, incluyan necesariamente la garantía de niveles determinados de eficacia o seguridad, en condiciones objetivas de determinación, y supongan controles técnicos, profesionales o sistemáticos de calidad, hasta llegar en debidas condiciones al consumidor y usuario. 
establecimientos mercantiles, menciona en el apartado 1.C): los contratos celebrados en un medio de transporte público. Más adelante, concretamente en el art. $148^{108}$, se establece un régimen especial de responsabilidad aplicable a una serie de servicios y, entre ellos, se mencionan los relativos a medios de transporte. Por ello cabría afirmar «la inclusión de la reclamación de responsabilidad del viajero al transportista en este especial sistema de responsabilidad objetiva donde el criterio de imputación deja de ser la culpa de este y donde además le bastará con probar a aquel que el daño le fue causado por el uso del servicio en cuestión» ${ }^{109}$.

Además, hay que destacar que cesa la responsabilidad del transportista que consiga probar que los daños se han producido, o bien por la conducta negligente del viajero que ha sufrido los daños, o bien por una fuerza mayor extraña a la conducción o al funcionamiento del vehículo; no se considerarán casos de fuerza mayor los defectos del vehículo ni la rotura o fallo de alguna de sus piezas o mecanismos ${ }^{110}$.

Por otro lado, surge basada en el Real Decreto 1575/1989, de 22 de diciembre, una responsabilidad civil objetiva, que, denominada acción del seguro obligatorio de viajeros, supone un planteamiento distinto del sistema tradicional de responsabilidad por culpa, dado que tal responsabilidad surge por el mero hecho de haberse sufrido por el viajero lesiones mientras era transportado y sin que tenga que alegar incumplimiento o negligencia por la porteadora para que funcione la garantía ${ }^{111}$. En caso de muerte del viajero que provocó el accidente por imprudencia, exime de responsabilidad a la

En todo caso, se consideran sometidos a este régimen de responsabilidad los servicios sanitarios, los de reparación y mantenimiento de electrodomésticos, ascensores y vehículos de motor, servicios de rehabilitación y reparación de viviendas, servicios de revisión, instalación o similares de gas y electricidad y los relativos a medios de transporte [...].

${ }^{109}$ Rojo Álvarez-MANZANEDA, C., La responsabilidad civil por daños causados por servicios defectuosos. Daños a la salud y seguridad de las personas, ob. cit., p. 388. La autora hace las citadas consideraciones basándose en algunos artículos, entre ellos, el art. 28 de la Ley 26/1984, de 19 de julio, General para la Defensa de los Consumidores y Usuarios. Del mismo modo, la doctrina jurisprudencial que presenta toma como base la citada ley, cf. ibidem, pp. 388-389.

${ }^{110}$ Cf. el art. 1.1. ap. 2 del Real Decreto Legislativo 8/2004, de 29 de octubre, por el que se aprueba el texto refundido de la Ley sobre Responsabilidad Civil y Seguro en la circulación de Vehículos a Motor.

${ }^{111}$ Sobre el particular, véanse, por ejemplo, SAP de Córdoba, de 12 marzo de 2004; SAP de Sevilla, de 3 septiembre de 2001; SAP de Almería de 10 de febrero de 2000; SAP de Málaga de 22 de mayo de 2000; SAP Barcelona de 6 de mayo de 1994.

${ }^{112} \mathrm{El}$ art. 8 establece que «la protección del seguro no alcanzará a los asegurados que provoquen los accidentes en estado de embriaguez o mediante la comisión de actos dolosos o con imprudencia o infracción de los reglamentos y disposiciones vigentes sobre el transporte público colectivo». Sobre el particular, véase la SAP de Vizcaya de 28 de enero de 1993, en la que se refiere a la muerte de un viajero con ocasión de un viaje en tren, siendo la culpa exclusiva del fallecido. 
entidad transportista y de la obligación de indemnizar a sus causahabientes, por no estar tal supuesto contemplado en el Reglamento del Seguro Obligatorio de Viajeros (art. 8) ${ }^{112}$.

\section{Responsabilidad por los daños personales como consecuencia del trans- porte marítimo de viajeros}

Desde los orígenes de la navegación por mar el buque ha sido utilizado para el transporte de personas, no obstante hay que destacar que el transporte de personas en barco como actividad autónoma tiene lugar en la segunda mitad del siglo XIX ${ }^{113}$. Por otro lado, la mayor perfección y seguridad de los medios de navegación, el establecimiento de sus líneas regulares y el incremento del turismo atribuyen gran importancia económica a esta forma de explotación o de utilización del buque ${ }^{114}$.

En cuanto a la responsabilidad del porteador por los daños ocasionados a las personas, tal y como se ha venido diciendo para el transporte terrestre de personas, como no es posible la extensión analógica de los preceptos relativos al transporte de cosas, regirán los preceptos comunes sobre culpa y responsabilidad contractual, a no ser que existan disposiciones especiales ${ }^{115}$. Más concretamente, hablando del pasaje marítimo, Sánchez Calero observa lo siguiente ${ }^{116}$ : «la responsabilidad contractual del porteador por los daños producidos por la muerte o lesiones del pasajero, carece de una oportuna regulación dentro de nuestro ordenamiento, que creemos ha de orientarse hacia un régimen imperativo, que no pueda ser eliminado por las cláusulas

${ }^{113}$ Sobre el particular, Broseta Pont, M. y Martínez SAnZ, F., Manual de Derecho mer-

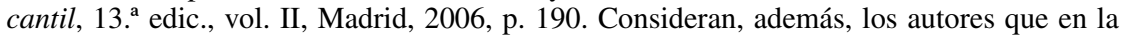
actualidad quizá los buques más costosos son precisamente los que se destinan al transporte de personas por mar, cf. ibidem.

${ }^{114}$ Ibidem, p. 190. Podemos referirnos a tres modalidades de contratos que tienen relación con el traslado de personas de un lugar a otro: el crucero marítimo, el pasaje y el fletamento de cruceros. En el crucero el organizador se obliga a trasportar a un colectivo de pasajeros mediante precio a una o varias localidades determinadas según un itinerario convenido, y a proporcionar otra serie de prestaciones a bordo o en tierra según las condiciones del contrato. El pasaje se caracteriza por el traslado de personas y sus equipajes de un lugar a otro, de forma que las eventuales prestaciones de cabina y alojamiento son accesorias respecto de la prestación fundamental de transporte; por otro lado, si los servicios al pasajero constituyen el objeto del contrato de crucero, la puesta a disposición del buque, en condiciones de realizar viajes de crucero, es el objeto del fletamento de cruceros. En el fletamento, el pasajero o el colectivo de pasajeros no son parte contractual; sobre el particular, véase, Arroyo Martínez, I., Curso de Derecho marítimo, Barcelona, 2001, pp. 561-562.

${ }^{115}$ Entre otros, véase URÍA, R., Derecho mercantil, ob. cit., p. 662. GARRIGUES, J., Curso de Derecho mercantil, ob. cit., p. 234.

${ }^{116}$ Sánchez Calero, F., Instituciones de Derecho mercantil, ob. cit., p. 563.

117 Vid. Arroyo Martínez, I., Curso de Derecho marítimo, ob. cit., pp. 561-562. 
de exoneración de responsabilidad, y hacia el establecimiento de la responsabilidad objetiva del porteador, con ligeras excepciones, si bien ha de admitirse la posibilidad de fijar una limitación a su deuda».

La codificación del contrato de transporte marítimo de personas explica, probablemente, que la mayor parte de nuestra doctrina ${ }^{117}$ opte por considerar de carácter contractual la responsabilidad por los daños personales sufridos por los pasajeros durante la fase de ejecución del transporte. «Esta solución parece la más natural pues los daños nacen en el contexto relacional de un negocio jurídico específicamente previsto en nuestro Código de Comercio cuyo contenido obligacional concreto se establece con detalle en formularios tipo predispuestos por las compañías navieras que ordenan el comportamiento de cada una de las partes durante el transporte» ${ }^{118}$. En definitiva es una responsabilidad contractual que nace del incumplimento. Por estas razones «extraer del ámbito del contrato los daños que el pasajero pueda sufrir en el desarrollo del viaje parece un artificio poco justificable dogmáticamente» ${ }^{119}$. No obstante, con la finalidad de conseguir una protección mayor de los pasajeros, el naviero tiene la obligación de concertar un seguro obligatorio que cubra las responsabilidades por muerte o lesiones de los pasajeros ${ }^{120}$.

Del mismo modo, conviene tener en cuenta que «el azar que históricamente presentaban los viajes por mar, justificaban un sistema de responsabilidad por daños que no penalizase excesivamente al naviero». Ahora bien, en nuestra época puede dudarse razonablemente de que los viajes por mar continúen presentando las condiciones especialmente azarosas que motivaron un régimen tan laxo de responsabilidad para el transportista marítimo ${ }^{121}$. Por ello en el Proyecto de Ley General de la Navegación Marítima, en el art. 355, se refiere a criterios de responsabilidad objetiva.

En el ámbito internacional el contrato de pasaje se rige por el Convenio de Atenas de 13 de diciembre de 1974, sobre transporte de pasajeros y sus equipajes por mar. El citado Convenio se centra de forma prácticamente exclusiva en la responsabilidad del transportista marítimo por los daños personales (muerte o lesiones) o materiales causados al pasajero como consecuencia de un accidente. Por otro lado, hay que tener en cuenta el Protocolo de 2002 al Convenio de Atenas en el que, entre otras cosas, se introducen por primera vez en este ámbito criterios de responsabilidad objetiva por los daños ocasionados en la navegación.

118 Castilla Cubillas, M., La responsabilidad civil por daños causados por servicios defectuosos, ob. cit., p. 447.

${ }^{119}$ Ibidem.

${ }^{120}$ Reglamento del Seguro Obligatorio de Viajeros, Real Decreto 1575/1989, de 22 de diciembre.

${ }^{121}$ Castilla Cubillas, M., La responsabilidad civil por daños causados por servicios defectuosos, ob. cit, p. 448. 


\section{Responsabilidad por los daños debidos a la muerte o lesiones personales en el transporte aéreo de viajeros}

Es evidente que en el régimen del transporte aéreo la cuestión fundamental es la responsabilidad del porteador y en el ordenamiento español está regulada tanto en la Ley de Navegación Aérea como en los Convenios internacionales ${ }^{122}$. Más concretamente, la Ley sobre la Navegación Aérea ${ }^{123}$ (LNA), inspirándose en lo básico en el Convenio de Roma, ya estableció en 1960 el principio de responsabilidad limitada y garantizada de forma común para los viajeros y las personas o cosas que se encuentren en la superficie ante los daños sufridos por estos en caso de accidente aéreo ${ }^{124}$.

Es la citada ley la que, con carácter especial respecto a lo establecido en el Código civil, regula la responsabilidad del transportista aéreo en caso de accidente. Concretamente, dentro de la evolución experimentada por la responsabilidad extracontractual, "se considera que en determinados ámbitos del actuar humano, tales como en materia de navegación aérea o energía nuclear, se llega a prescindir del elemento de la culpa, apreciándose responsabilidad reparadora del perjuicio con la sola constancia del daño causado por el ejercicio de tales actividades, que se denomina responsabilidad objetiva» ${ }^{125}$.

La LNA citada, en su capítulo XIII, bajo la rúbrica «De la responsabilidad en caso de accidente» (en los artículos 116 a 125), trata de forma conjunta la responsabilidad derivada del contrato de transporte aéreo y la de carácter extracontractual. Más concretamente, dentro del citado capítulo, el art. 120 LNA recoge el fundamento de esta responsabilidad de carácter obje-

${ }^{122}$ El régimen contenido en las citadas normas responde a tres principios esenciales: responsabilidad objetiva, limitada e inderogable; véase URíA, R. Y MenÉndeZ, A., Curso de Derecho mercantil, Tomo II, Madrid, 2001, p. 1414.

${ }^{123}$ Ley 48/1960, de 21 de julio. En el art. 5 de la citada ley dice que regula «la navegación aérea nacional».

${ }^{124}$ El Real Decreto 37/2001, de 19 de enero, ha actualizado la cuantía de las indemnizaciones por daños previstas en la Ley 48/1960, de 21 de julio, de Navegación Aérea. En la Exposición de Motivos del citado Real Decreto se dice que se ha considerado necesario establecer la aplicación de las indemnizaciones recogidas en el art. 1 de este Real Decreto, a los alumnos pilotos, a los ocupantes de vuelos de iniciación o panorámicos que no constituyen transporte y a los ocupantes de aeronaves dedicadas a trabajos aéreos comerciales que no formen parte de la tripulación.

${ }^{125}$ Sobre el particular, Bustos MoReno, Y., La responsabilidad civil en la navegación aérea. Los daños a terceros, Madrid, 2003, p. 73. En relación con los daños ocasionados a los pasajeros, podemos citar el trabajo de Quintana CARLO, I., La responsabilidad del transportista aéreo por daños a los pasajeros, Salamanca, 1977; se trata de una monografía que sigue siendo un punto de referencia ineludible sobre la materia de la que trata. Ya en fechas más próximas, véase GUERRERO LEBRÓN, M. ${ }^{a}$ J., La responsabilidad contractual del porteador aéreo en el transporte de pasajeros, Valencia, 2005. 
tivo para ambos supuestos y se expresa en los siguientes términos: «la razón de indemnizar tiene su base objetiva en el accidente o daño y procederá, hasta los límites de responsabilidad que en este capítulo se establecen, en cualquier supuesto, incluso en el de accidente fortuito y aun cuando el transportista, operador o sus empleados justifiquen que obraron con la debida diligencia». Se declaran también indemnizables por la ley los daños que se causen a las personas o a las cosas que se encuentren en la superficie terrestre por acción de la aeronave, en vuelo o en tierra, o por cuanto de ella se desprenda o se arroje (cf. art. 119).

En definitiva en el ámbito interno se trata de una responsabilidad objetiva, es decir, aunque no haya incurrido en culpa el porteador, por todos los daños que se produzcan con ocasión de la navegación o viaje. En esta línea se manifiesta la sentencia de la Audiencia Provincial de Lleida de 12 de abril de 2000, donde se dice, entre otras cosas, que la responsabilidad contemplada en la citada ley «es de carácter objetivo como así se reconoce en el art. 120 al decir que la razón de indemnizar tiene su base objetiva en el accidente o daño [...].

También hay que dejar constancia de que respecto a los daños ocasionados a terceros, el establecimiento de un régimen de responsabilidad no constituyó ninguna singularidad en comparación con el Convenio de Roma y con el sistema predominante en otros Códigos aeronáuticos, aunque sí respecto a la situación precedente en España, donde se aplicaba el régimen de responsabilidad extracontractual previsto por el Código.

Por otro lado, como se establece en la sentencia del Tribunal Supremo de 17 de diciembre de 1990, el art. 120 de la LNA, así como también el art. 17 del Convenio de Varsovia, ambos preceptos sancionan, «aun aparte de la estricta responsabilidad objetiva, una responsabilidad por riesgo, fundada en la coacción social que impone la asunción de peligros por los perjudicados y que se desplaza sobre aquel que, aunque en forma lícita y permitida ha creado los riesgos; frente a los que el eventual perjudicado carece de estructuras o medios propios de defensa como ocurre, por ejemplo, en la navegación aérea en sus diversas facetas de operaciones en tierra o en el aire. La coacción que somete al particular a los riesgos creadores de responsabilidad para quien creó esos riesgos».

La tutela del interés de los pasajeros justifica que la legislación especial opte, bien por un sistema de responsabilidad objetiva, bien por un sistema de responsabilidad basado en la culpa presunta. En esta consideración influye la creación del riesgo y la dificultad técnica de conocer las verdaderas causas del siniestro, que agravan la capacidad de pruebas del perjudicado ${ }^{126}$.

La citada responsabilidad se presenta limitada, como norma general, para el sujeto responsable; esta responsabilidad se hace ilimitada cuando

${ }^{126}$ URÍA, R., y MenÉndeZ, A., Curso de Derecho mercantil, ob. cit., pp. 1414-1415. 
existe dolo o culpa grave del porteador o sus auxiliares según se establece en el art. 121 de la ley, donde se dispone lo siguiente: no obstante lo dispuesto en el artículo anterior, el transportista u operador responderá de sus propios actos y de los de sus empleados, y no podrán ampararse en los límites de responsabilidad que en este capítulo se establecen, si se prueba que el daño es el resultado de una acción u omisión suya o de sus dependientes, en la que exista dolo o culpa grave. En el caso de los empleados habrá de probarse, además, que estos obraban en el ejercicio de sus funciones» ${ }^{127}$.

Hay que tener en cuenta asimismo que el transporte combinado entre varias empresas de navegación aérea las constituye en responsables solidarias, y puede elegir el expedidor o destinatario para la reclamación correspondiente cualquiera de las que han tomado parte en el transporte (art. 110). Es evidente que se trata de un precepto de gran modernidad, pues supera la distinción entre porteador contratante y efectivo, y hace solidariamente responsables a todos los que de alguna manera han intervenido en la operación de transporte ${ }^{128}$.

Finalmente, en el ámbito interno, habrá que tener en cuenta la normativa que protege los derechos de los consumidores y usuarios. La consideración del contrato de transporte -en sus distintas modalidades, terrestre, marítimo y aéreo- como un contrato de consumo y del pasajero como consumidor o usuario permite la aplicación de la actual normativa para la defensa de sus derechos y la indemnización por los daños y perjuicios ocasionados por el porteador.

En el ámbito internacional son de aplicación las normas del Convenio de Varsovia de 12 de octubre de 1929, ratificado por España en 1930 y modificado, entre otros, por el Protocolo de La Haya de 28 de septiembre de 1955 y los Protocolos suscritos en Montreal el 25 de septiembre de 1975.

En primer lugar, en el Convenio de Varsovia, y por lo que respecta a la responsabilidad por los daños personales ocasionados al viajero, el art. 17 de este establece la responsabilidad del porteador por el daño ocasionado, entre otros, en caso de lesión corporal sufrida por cualquier viajero, cuando el accidente que ha causado el daño se haya producido a bordo de la aeronave $o$ en el curso de todas las operaciones de embarque o desembarque. Sin embargo, no será responsable el porteador si prueba «que él y sus comisionados han tomado todas las medidas necesarias para evitar el daño o que les fue imposible tomarlas», según establece el art. 20.1 del citado Convenio. Además, si prueba «que la persona lesionada ha sido causante del daño o ha

${ }^{127}$ Sobre el particular, cf. la STS de 28 de mayo de 2007 en la que se declara que « la responsabilidad objetiva se combina con una responsabilidad por dolo o culpa grave, para la que no operan los límites establecidos en los artículos 117 y 120 LNA y que está recogida en el artículo $121 \mathrm{LNA»;} \mathrm{cf.,} \mathrm{asimismo,} \mathrm{la} \mathrm{STS} \mathrm{de} 22$ de septiembre de 2005.

${ }^{128}$ En este sentido se ha pronunciado la STS de 17 de diciembre de 1990. 
contribuido al mismo, el Tribunal podrá, con arreglo a las disposiciones de su propia Ley, descargar o atenuar la responsabilidad del porteador», cf. art. 21. Por otro lado, en el artículo siguiente limita la responsabilidad del porteador, cf. art. 22.1. En definitiva, en el citado Convenio de Varsovia se establece una responsabilidad limitada y por culpa presunta.

En 1999 se firmó en Montreal ${ }^{129}$ un nuevo convenio internacional sobre esta materia ${ }^{130}$, en el que la Comunidad Europea fue parte contratante, entró en vigor en España el 28 de junio de 2004. Establece el citado Convenio en el art. 17.1 que «el transportista es responsable del daño causado en caso de muerte o de lesión corporal de un pasajero por la sola razón de que el accidente que causó la muerte o lesión se haya producido a bordo de la aeronave o durante cualquiera de las operaciones de embarque o desembarque» ${ }^{131}$. Ahora bien, si la indemnización excede de $100.000 \mathrm{DEG}^{132}$, el transportista no será responsable si prueba que aquel no se debió a la negligencia o a otra acción u omisión indebida del transportista o sus dependientes o agentes, o que el daño se debió únicamente a la negligencia o a otra acción u omisión indebida de un tercero, cf. art. 21.2 CM.

Por otro lado, el transportista podrá exonerarse total o parcialmente de responsabilidad si prueba que la negligencia u otra acción u omisión indebida del pasajero, de la persona que pide indemnización, o de otra persona de la que proviene su derecho, causó el daño o contribuyó a él, según se establece en el artículo 20 del citado Convenio.

${ }^{129}$ Uno de los grandes objetivos de la Comunidad Internacional en los últimos años ha sido el asegurar una cobertura adecuada a los usuarios del transporte aéreo en caso de accidentes con resultado de muerte o lesión.

${ }^{130}$ Del mismo modo, otro de los importantes objetivos de esta normativa es lograr que se dé una adecuada información al pasajero sobre los derechos que le asisten.

${ }^{131}$ Como se puede comprobar en el precepto transcrito, no se hace mención alguna a los daños morales; debido a ello, su interpretación ha originado un importante debate acerca de si están o no incluidos en el precepto los daños morales que pueda sufrir el pasajero. Sobre

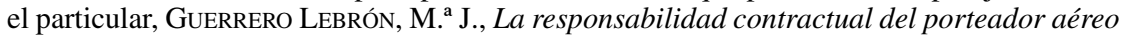
en el transporte de pasajeros, ob. cit., pp. 146-ss. y la bibliografía que cita la autora en torno al citado debate.

${ }^{132}$ Derechos especiales de giro (del Fondo Monetario Internacional). 